$\begin{array}{llll}\text { Submission: } 07 / 10 / 2020 ; & 1^{\text {st }} \text { round notif.: } 18 / 12 / 2020 ; & \text { New version: } 12 / 01 / 2020 ; & 2^{\text {nd }} \text { round notif.: } 02 / 02 / 2021 ; \\ \text { Camera ready: } 16 / 02 / 2021 ; & \text { Edition review: } 19 / 02 / 2021 ; & \text { Available online: } 12 / 03 / 2021 ; & \text { Published: } 12 / 03 / 2021 ;\end{array}$

\title{
Percepção de Docentes que lecionam Programação de Computadores quanto à Formação Pedagógica
}

\author{
Title: Perception of Teachers who teach Computer Programming regarding Pedagogical \\ Formation
}

\author{
João Henrique Berssanette \\ Instituto Federal do Paraná \\ joao.berssanette@ifpr.edu.br
}

\author{
Antonio Carlos de Francisco \\ Universidade Tecnológica Federal do Paraná \\ acfrancisco@utfpr.edu.br
}

\begin{abstract}
Resumo
Os cursos da área de computação e informática nos diferentes níveis de ensino possuem, como uma de suas metas, capacitar os estudantes a programar computadores. No entanto, a literatura tem evidenciado que os docentes, ao ensinar programação, têm obtido menos êxito do que deveriam e precisariam ter. Nessa direção, considerando que pelo menos uma parte das dificuldades relativas ao processo de ensino/aprendizagem de programação pode estar relacionada à formação pedagógica ou à ausência dela pelos docentes, objetivou-se, neste estudo, investigar a percepção de docentes quanto à formação pedagógica e ao processo de ensino/aprendizagem de programação. Para tanto, foi desenvolvido um estudo exploratório de abordagem qualitativa, com docentes das áreas de computação, informática e afins, que lecionaram alguma disciplina relacionada à programação nos últimos cinco anos. Por intermédio da análise dos dados coletados, observou-se que os docentes com formação pedagógica participam mais de atividades direcionadas ao exercício do magistério durante a graduação, bem como possuem uma percepção positiva da preparação fornecida pelo ensino superior para exercer a docência, quando em comparação aos docentes que não possuem essa formação. Verificou-se, ao se comparar as práticas pedagógicas, conteúdos, recursos e tecnologias, instrumentos e técnicas avaliativas, além das atitudes de aprendizagem e perfil dos estudantes e turmas a que foram expostos enquanto eram estudantes e que expõem seus alunos agora como docentes, que a maior parcela, tanto dos docentes com formação pedagógica quanto os sem essa formação, indica que essa série de elementos é semelhante em muitos aspectos. Ademais, ambos os grupos de professores consideram importante ter uma prática docente embasada por teorias de aprendizagem e metodologias de ensino/aprendizagem, considerando também que que a pós-graduação contribuiu em sua preparação para o exercício do magistério.
\end{abstract}

Palavras-Chave: Programação de Computadores. Ensino/Aprendizagem. Formação Pedagógica.

\begin{abstract}
The courses in computing and informatics at different levels of education have, as one of their goals, empower students to program computers. However, the literature has shown that teachers, when teaching programming, have been less successful than they should and would need to have. In this sense, considering that at least part of the difficulties related to the teaching/learning process of programming may be related to pedagogical formation or the absence of it by teachers, this study aimed to investigate the perception of teachers regarding the pedagogical formation and the teaching/learning process of programming. To this end, an exploratory study of qualitative approach was developed, with teachers from computing, informatics, and the like, who taught some discipline related to programming in the last five years. Through the analysis of the collected data, it was observed that teachers with pedagogical formation participate more in activities directed to the exercise of teaching during graduation, as well as have a positive perception of the preparation provided by higher education to practice teaching when compared to teachers who do not have this formation. It was also verified when comparing the pedagogical practices, contents, resources and technologies, instruments and evaluative techniques, in addition to the learning attitudes and profile of students and classes to which they were exposed while they were students and that expose their students now as teachers, that the largest portion, both of teachers with the pedagogical formation and those without this formation, indicated that this series of elements are similar in many respects. Moreover, both groups of teachers consider it
\end{abstract}

Cite as: Berssanette, J. H., \& de Francisco, A. C. (2021). Perception of Teachers who teach Computer Programming regarding Pedagogical Formation (Percepção de Docentes que lecionam Programação de Computadores quanto à Formação Pedagógica). Brazilian Journal of Computers in Education (Revista Brasileira de Informática na Educação - RBIE), 29, 133-159. DOI: 10.5753/RBIE.2021.29.0.133 
important to have a teaching practice based on learning theories and teaching/learning methodologies, considering that graduate studies contributed to their preparation for the teaching exercise.

Keywords: Computer Programming. Teaching/Learning. Pedagogical Formation.

\section{Introdução}

Em virtude da relevância dos computadores para a sociedade, tem-se notabilizado o fomento das habilidades relacionadas à programação de computadores. Nesse sentido, o desenvolvimento dessas habilidades na educação formal passa, invariavelmente, pelo processo de ensino/aprendizagem de programação de computadores.

No entanto, no que tange ao processo de ensino/aprendizagem de programação, a literatura da área tem evidenciado que os docentes, ao ensinar programação, têm obtido menos êxito do que deveriam e precisariam ter (McGettrick et al., 2005; Qian \& Lehman, 2017; Robins, 2019; Vihavainen et al., 2014; Watson \& Li, 2014).

Dessa forma, o que se tem observado é que as disciplinas introdutórias que tratam da programação de computadores estão, geralmente, relacionadas a elevados níveis de insucesso (reprovações), bem como a elevadas taxas de desistência, sendo estas relacionadas ao abandono do curso (Bennedsen \& Caspersen, 2007; Simon et al., 2019; Watson \& Li, 2014).

Assim, o processo de ensino/aprendizagem de programação tem se constituído um desafio para docentes e estudantes, fazendo com que esse aprendizado possa ser considerado um dos gargalos existentes em cursos de computação, informática e afins. Isso possibilita que o ensino de programação seja considerado um dos grandes desafios na educação em computação (Caspersen, 2007; McGettrick et al., 2005; Sleeman, 1986).

A origem dos problemas associados ao processo de ensino/aprendizagem de programação é muito ampla, uma vez que envolve diversas variáveis de atores diferentes. Esses problemas têm sido amplamente discutidos pela comunidade acadêmica da área que apresenta causas, como a falta de competências na resolução de problemas, poucas habilidades matemáticas, baixo nível de abstração, dificuldades de interpretação do problema e compreensão de texto por parte dos estudantes.

Em decorrência dessas dificuldades observadas e com o intuito de reverter esse cenário, professores e pesquisadores têm se dedicado a estudar as causas, bem como desenvolver propostas variadas voltadas, especialmente, para aprendizes novatos em programação, que visam, de algum modo, tornar o processo de ensino/aprendizagem de programação mais efetivo.

Entretanto, cabe salientar que nenhuma delas se mostrou completa ou, até mesmo, genérica, a ponto de sanar as dificuldades, de forma que os problemas inerentes ao aprendizado de programação ainda persistem. Desse modo, os estudantes continuam lutando para aprender a programar, por razões que a hipótese não deve apenas ser restrita a aspectos cognitivos.

Dessa maneira, deve-se, ao menos, considerar que uma parte dos problemas concernentes ao aprendizado de programação pode ter sua origem nas práticas docentes desenvolvidas no processo de ensino/aprendizagem, relacionando-se à formação pedagógica (ou não formação) desses docentes.

Por formação pedagógica, entendem-se os cursos de nível superior de licenciatura e seus equivalentes, bem como alguns cursos de especialização (lato sensu) que visam instrumentalizar profissionais que almejam exercer o magistério nas diferentes modalidades e níveis de ensino.

Com base nesse contexto, o desenvolvimento deste trabalho teve como objetivo investigar a percepção de docentes que lecionam disciplinas relacionadas à programação de computadores, quanto à formação pedagógica e ao processo de ensino/aprendizagem de programação. 
Dentre as principais contribuições deste estudo, encontram-se: a percepção dos docentes quanto à preparação de sua formação para exercer a docência, bem como para ensinar programação; a importância de embasar sua prática em teorias de aprendizagem e metodologias de ensino/aprendizagem; e a comparação de elementos a que os docentes foram expostos durante o aprendizado de programação enquanto eram estudantes e os que expõem seus alunos agora como professores.

Compete registrar que este artigo corresponde a um pequeno recorte de um estudo exploratório relacionado à tese de doutorado do primeiro autor, intitulada "Metodologias ativas de aprendizagem e teoria da carga cognitiva para construção de "novos" caminhos no ensino de programação de computadores", que se encontra em fase de finalização.

O presente texto está organizado da seguinte forma: na Seção 2, apresentam-se os trabalhos relacionados; na Seção 3, contextualiza-se o processo de ensino/aprendizagem de programação; na Seção 4, destacam-se a formação e o perfil do docente que leciona programação; na Seção 5, são evidenciados os procedimentos metodológicos; na Seção 6, realiza-se a caracterização da amostra; na Seção 7, são apresentados os resultados, a análise e a discussão destes; e, na Seção 8, salientam-se as considerações finais e as sugestões para estudos futuros.

\section{Trabalhos Relacionados}

Inicialmente, cumpre destacar que a literatura no contexto do ensino/aprendizagem de programação de computadores dispõe de um vasto volume de pesquisas. Contudo, uma grande parte dessas pesquisas tem, em sua origem, as dificuldades apresentadas pelos estudantes durante o processo de ensino/aprendizagem de programação.

No entanto, deve-se considerar que ao menos uma parte dos problemas concernentes à aprendizagem de programação pode ter uma relação direta com os processos de ensino e, por consequência, aos docentes e à formação deles, podendo implicar, direta ou indiretamente, dificuldades inerentes aos estudantes, bem como aos conteúdos.

Nesse âmago, observa-se que poucos estudos buscam investigar a relação entre as dificuldades inerentes aos docentes, bem como à sua formação para o ensino de programação. A seguir, são apresentados alguns trabalhos relacionados a esse contexto.

Lima (2018) sistematizou algumas das concepções docentes acerca do ensino de programação de computadores. Os resultados do estudo indicaram a importância da reflexão docente sobre as estratégias de ensino e a indispensável experiência profissional na área para qual se ensina. Além disso, o estudo revela que a ausência de formação pedagógica é um fator de insegurança para os docentes, os quais vêm de cursos que enfocam a parte técnica da computação. Por fím, o autor aponta para o fato de que a atuação didática dos professores precisa transcender a pedagogia transmissiva, envolvendo estratégias que estimulem a autonomia e a autoria discente em ambientes de programação de computadores.

GURER et al. (2019) investigaram os fatores que afetam as atitudes dos professores de informática em formação, no que compete à programação de computadores. Segundo os autores, os resultados revelaram que professores em formação com atitudes moderadamente elevadas em relação à programação possuíam correlações significativas com os seus resultados, autoeficácia e aprendizagem percebida em cursos de programação.

Oliveira e Cambraia (2020) discutem uma série de desafios relacionados ao processo formativo de professores para o ensino de computação na educação básica, no Brasil. A partir das análises dos estudos publicados no V Workshop da Licenciatura em Computação, os autores 
apresentam uma série de desafios associados a direcionamentos que podem ser usados no intuito de alavancar a qualidade do curso e do ensino de computação no Brasil.

O estudo de Kretzer et al. (2020) parte de iniciativas que visam integrar a formação em computação de maneira interdisciplinar, voltada a professores de outras áreas por meio de formação continuada. Na pesquisa, os autores apresentam um mapeamento sistemático que visa à identificação de unidades instrucionais existentes para a formação continuada de professores e suas características.

Este artigo, nessa acepção, contempla diversos elementos dos trabalhos relacionados nesta seção. Entretanto, a abordagem proposta se difere das mencionadas, pois parte da percepção de docentes que lecionam disciplinas relacionadas à programação, com vistas a investigar uma série de elementos concernentes à formação pedagógica e, por certo, ao processo de ensino/aprendizagem de programação. Destaca-se que o intuito perpassa pela exploração de que essas percepções possam apresentar novos elementos vinculados à temática.

\section{Processo de Ensino/Aprendizagem de Programação de Computadores}

Os cursos da área de computação e informática nos diferentes níveis de ensino possuem, como uma de suas metas, capacitar os estudantes a programar computadores. Dessa forma, aprender a programar computadores é uma das bases na formação de estudantes nesses cursos e pode ser considerado algo fundamental na formação de estudantes que terão, no desenvolvimento de softwares, o produto final de seu trabalho.

Assim, a aprendizagem de programação é essencial para todas as carreiras ligadas à computação e à informática, sendo importante, também, em outras áreas próximas, normalmente definidas como STEM (sigla em inglês para Science, Technology, Engineering and Mathematics). Entretanto, aprender a programar computadores não é uma tarefa simples, tampouco trivial. A literatura ao longo dos anos tem evidenciado que o processo de ensino/aprendizagem de programação se constitui um desafio para professores e estudantes.

As dificuldades relacionadas ao processo de ensino/aprendizagem dos conteúdos introdutórios de programação consistem em um fato reconhecido e amplamente discutido na comunidade acadêmica da área, seja no exterior (Gomes \& Mendes, 2014; Koulouri et al., 2015; Luxton-Reilly, Sheard, et al., 2018b, 2018a; Medeiros et al., 2019; Qian \& Lehman, 2017; Robins, 2019; Simon et al., 2019), seja no Brasil (Arimoto \& Oliveira, 2019; Berssanette \& Frencisco, 2018; Bosse \& Gerosa, 2015; Coutinho et al., 2017; Holanda et al., 2019; Lopez et al., 2019; Silva et al., 2015; Souza et al., 2016).

Em decorrência das diversas dificuldades concernentes ao processo de ensino/aprendizagem de programação de computadores, muitos estudantes, geralmente, apresentam um fraco desempenho, outros chegam a considerar essa matéria um obstáculo muito difícil de transpor e, por isso, eles se desmotivam. Em razão dessa realidade, cabe destacar que o alto índice de reprovação e abandono nessas disciplinas introdutórias de programação é um fato também reconhecido pelos pesquisadores da área (Bennedsen \& Caspersen, 2007; Costa et al., 2017; McGettrick et al., 2005; Simon et al., 2019; Watson \& Li, 2014).

Estudos como o de Bennedsen e Caspersen (2007), Watson e Li (2014), Bosse e Gerosa (2015) e Simon et al. (2019) indicam que os índices de insucesso em disciplinas introdutórias de programação giram em torno de $30 \%$, o que faz com que essas disciplinas possam ser consideradas um dos gargalos existentes em cursos de computação, informática e outros que contemplam, em sua matriz curricular, tais disciplinas, dificultando ou, até mesmo, impedindo a continuidade dos estudantes nos cursos. 
Além disso, alguns pesquisadores como Giraffa e Mora (2016), Iqbal Malik e ColdwellNeilson (2017), Luxton-Reilly, Becker, et al. (2018) e Pattanaphanchai (2019) evidenciam uma correlação entre os elevados níveis de insucesso (reprovação) em disciplinas introdutórias de programação com as elevadas taxas de desistência e abandono do curso.

Nesse cenário, Martins et al. (2018) expõem que o ensino de programação enfrenta sérios desafios no mundo. Muitos estudantes abandonam os cursos de ciência da computação em seus primeiros anos, porque eles não são capazes de entender os conceitos ensinados nos cursos introdutórios de programação.

A origem dos problemas associados ao processo de ensino/aprendizagem de programação é muito ampla, uma vez que envolve diversas variáveis. Nesse âmago, Yousoof e Sapiyan (2016) elucidam que uma parte desses problemas está relacionada à própria natureza da programação, que é uma habilidade altamente cognitiva e requer domínio de múltiplos domínios.

Assim, podemos considerar que a programação não é uma habilidade única, mas um conjunto de recursos (habilidades, competências, experiências) associados a uma atividade cognitiva complexa, na qual programadores experientes podem aplicar simultaneamente várias habilidades cognitivas de ordem superior para elaborar soluções aos problemas do mundo real e implementálas em um ambiente computacional.

Todavia, mesmo considerando a natureza complexa da programação, não se deve fortalecer a crença de que alguns nascem programadores e outros não, pois a programação não é uma habilidade inata; portanto, essa habilidade pode ser adquirida e aprimorada (Guzdial, 2015).

No Brasil, o aprendizado de programação, na educação formal, ocorre por meio de um conjunto de disciplinas introdutórias que são identificadas por diversos nomes, como: algoritmos, lógica de programação, linguagem de programação, técnicas de programação e outros.

Essas disciplinas introdutórias de programação visam fornecer aos estudantes os fundamentos de programação. Geralmente, isso representa um conjunto pequeno de comandos e conceitos, dos quais os aprendizes devem se utilizar para implementar soluções a um determinado problema e representá-lo em um ambiente computacional.

Bennedssen e Caspersen (2008) destacam que um dos objetivos mais importantes de uma disciplina introdutória de programação é que os estudantes aprendam uma abordagem sistemática para desenvolver programas computacionais.

As Diretrizes Curriculares Nacionais para os cursos de Graduação em Computação (DCN16) mencionam a programação nos itens I e III do art. $5^{\circ}$, o qual postula:

Art. $5^{\circ}$ Os cursos de bacharelado e licenciatura da área de Computação devem formar egressos que revelem pelo menos as competências e habilidades comuns para: I identificar problemas que tenham solução algorítmica; [...] III - resolver problemas usando ambientes de programação; [...] (MEC, 2016).

De um modo geral, em disciplinas introdutórias de programação, os conteúdos a serem trabalhados incluem, principalmente, a descrição dos passos necessários para se solucionar um problema, a implementação dessa solução em um ambiente computacional por meio da codificação, utilizando-se de uma linguagem de programação.

Nesse sentido, os conceitos e conteúdos tratados por essas disciplinas compreendem especialmente: entradas e saídas, constantes e variáveis, tipos primitivos de dados, instrução de atribuição, operadores aritméticos, relacionais e lógicos, estruturas de condição e repetição, 
estruturas de dados homogêneas e sub-rotinas (Luxton-Reilly \& Petersen, 2017; Qian \& Lehman, 2017; Schulte \& Bennedsen, 2006). Convém salientar que esses conceitos e conteúdos variam de acordo com os níveis de ensino e objetivos do curso, paradigma de programação, entre outros aspectos.

\section{Formação e Perfil do Docente que leciona Programação}

A princípio, com vistas a caracterizar a formação e o perfil do docente que leciona programação de computadores, faz-se necessário verificar onde ele atua. Observa-se que, no Brasil, o ensino/aprendizado dos conceitos relacionados à programação de computadores, na educação formal, é reservado, principalmente, aos estudantes que optam por cursos técnicos e de graduação na área da computação, informática e afins.

Dessa forma, afere-se que a formação desses docentes está diretamente relacionada com as áreas já elencadas, salvo algumas exceções. Assim, para a caracterização da formação desses docentes, faz-se preciso observar as Diretrizes Curriculares Nacionais para os cursos de Graduação em Computação (DCN16) (MEC, 2016), que regulamentam e orientam a formação inicial desses docentes.

A DCN16 institui as Diretrizes Curriculares para os cursos de graduação na área da Computação, abrangendo os cursos de bacharelado em Ciência da Computação, Sistemas de Informação, Engenharia de Computação, Engenharia de Software e licenciatura em Computação.

Além da DCN16, merecem destaque os Referenciais de Formação para os Cursos de Graduação em Computação, desenvolvidos pela Comissão de Educação da Sociedade Brasileira de Computação - SBC (Zorzo et al., 2017), que partem da referida DCN para nortear a elaboração de currículos para cada um dos cursos constantes nela.

Assim, ao se considerar que a formação inicial dos docentes que lecionam programação tem sua origem em cursos de bacharelado e de licenciatura da área de computação, nota-se que a referida DCN16 não aponta como competências esses cursos à docência em nível superior.

Destarte, o exercício do magistério em nível superior é regulamentado pela Lei de Diretrizes e Bases da Educação Nacional (LDB), de 1996, mais especificamente em seu art. 66 ${ }^{\circ}$, que aponta como exigência curso em nível de pós-graduação, prioritariamente em programas de mestrado e doutorado, para atuação no magistério em nível superior (BRASIL, 1996).

Ademais, convém observar que, no caso da docência em nível superior, o exercício do magistério é realizado por docentes que possuem distintas formações iniciais. Por esse motivo, dependendo do tipo de curso de graduação obtido, a formação pedagógica, embora seja importante, não é um impedimento para o exercício do magistério e, por isso, essa formação é adquirida por meio de uma segunda graduação, cursos de formação/complementação pedagógica, especialização, já que é possível encontrar uma parcela significativa de docentes sem nenhuma formação pedagógica.

Nessa direção, compete destacar que a LDB se pronuncia vagamente sobre a formação pedagógica do docente que exerce o magistério no nível superior, restringindo sua competência à área de conhecimento e atuação desses docentes, de modo a observar e requerer das instituições de ensino de nível superior, por meio de avaliações institucionais e de curso, apenas a titulação e o regime de trabalho do seu corpo docente.

A LDB também não especifica quanto ao exercício do magistério na educação profissional (nível técnico). Logo, nesse nível de ensino, o que se observa é a reprodução do que acontece no nível superior, salvo como exceção os cursos técnicos integrados ao ensino médio, os quais, por 
se situarem no nível da educação básica, abarcam a exigência de professores licenciados para atuação em seus cursos, conforme disposto no art. 62 da LDB (BRASIL, 1996).

Nessa seara, a DCN16, no art. $4^{\circ}, \S 5^{\circ}$, item IV, indica que os cursos de licenciatura em computação devem prover uma formação profissional que revele habilidades e competências para "atuar junto ao corpo docente das Escolas nos níveis da Educação Básica e Técnico e suas modalidades e demais organizações no uso efetivo e adequado das tecnologias da educação" (MEC, 2016).

Em síntese, o que se averigua é que os diversos cursos de graduação da área da computação formam: i) bacharéis (engenharia da computação, ciência da computação e sistemas de informação), com finalidades diversas relacionadas à área; ii) tecnólogos (análise e desenvolvimento de sistemas, gestão da tecnologia da informação, redes de computadores, sistemas para internet e outros) que se objetivam a formar profissionais aptos a atuar em um eixo tecnológico específico; e iii) licenciados (licenciatura em computação), com o intuito de atender à demanda de ensino de informática nas escolas de nível fundamental, médio e técnico (MEC, 2016; Zorzo et al., 2017).

Em teoria, os cursos de licenciatura em computação, devido ao direcionamento para o exercício do magistério, deveriam representar uma grande parte da formação inicial de docentes que atuam nos diferentes cursos da área, em comparação às demais graduações elencadas. No entanto, observa-se que os cursos de licenciatura em computação possuem, ainda, um alcance restrito, respondendo por apenas $3,47 \%$ dos cursos da área de computação no país, conforme o relatório de estatísticas da educação superior em computação no Brasil, produzido pela SBC (SBC, 2018).

Além disso, cabe averiguar que, no Brasil, o número de concluintes em cursos de licenciatura em computação é extremamente baixo, segundo a Sinopse Estatística da Educação Superior 2019. No referido ano, ingressaram em cursos de licenciatura em computação 3.063 estudantes; em contrapartida, concluíram o curso 786 estudantes, de forma que o percentual de concluintes corresponde a $25,66 \%$ do total de ingressos (INEP, 2020).

Dentro desse contexto, deve-se considerar que uma parcela significativa dos docentes que atuam nos cursos de computação e, portanto, lecionam matérias de programação de computadores, é oriunda de cursos superiores de bacharelado e tecnologia; por isso, muitos não possuem uma formação pedagógica, pois os conhecimentos relacionados ao processo de ensino/aprendizagem não são um dos enfoques desses tipos de curso.

Acerca do exposto, Génova e González (2017) enfatizam que:

Um engenheiro que se torna um educador em uma escola de engenharia de software tem, então, a missão de ensinar como projetar e construir sistemas de software, aplicando seus conhecimentos e experiência. No entanto, devido à sua formação em engenharia, os engenheiros podem esquecer que educar uma pessoa não é o mesmo que projetar uma máquina, pois uma máquina tem um objetivo bem definido, enquanto uma pessoa é capaz de autopropor os seus próprios objetivos (GÉNOVA; GONZÁLEZ, 2017, p. 1, tradução nossa).

Desse modo, nota-se que a lacuna referente aos conhecimentos pedagógicos sobre a condução do processo educativo direciona alguns docentes a utilizar como referência seus professores, reproduzindo, assim, os processos de ensino/aprendizagem a que foram expostos enquanto eram estudantes. 
Assim, na ausência de uma formação pedagógica, muitos docentes se percebem usando (ainda que inconscientemente) parâmetros, recursos ou modelos, com base em suas experiências prévias. Também acabam por desenvolver suas práticas como docentes sobre uma base empírica, mediante impressões acerca de seus mestres e pares ou sobre os casos de sucesso e insucesso.

No contexto do ensino de programação, Aureliano et al. (2016) evidenciam que o desafio de ensinar programação é proporcional ao de aprender. Por essa razão, muitas instituições de ensino escolhem como docentes para disciplinas introdutórias de programação professores mais experientes e com mais vivência em questões relacionadas ao ensino de programação.

Cumpre constatar que, no contexto da computação, como em diversas outras áreas, o que seleciona o docente são as suas competências em uma determinada área de conhecimento específico, ora obtidas por meio de uma formação inicial a partir da graduação, ora desenvolvidas posteriormente em cursos de pós-graduação (mestrado e doutorado) realizados no âmbito da formação técnica.

Todavia, deve-se considerar que os cursos de pós-graduação, principalmente stricto sensu (mestrado e doutorado), não se objetivam a formar ou preparar docentes para o exercício do magistério; visam, por sua vez, formar pesquisadores e, por isso, estão longe de atender à complexidade da atividade professoral, pois o exercício da docência exige não apenas o domínio de conhecimentos específicos ou competências técnicas, mas também os conhecimentos pedagógicos sobre a condução do processo educativo, além de um conjunto de competências essenciais para que se possa desenvolver uma prática docente de qualidade.

\section{Procedimentos Metodológicos}

Do ponto de vista de seus objetivos, o presente trabalho pode ser classificado como uma pesquisa exploratória, pois visa proporcionar uma maior familiaridade com as temáticas e as implicações delas com os problemas, com vistas a torná-los explícitos, construindo, assim, novas hipóteses.

O procedimento metodológico de interpelação dos dados é predominantemente qualitativo, porque considerou haver uma dinâmica referente aos objetivos da pesquisa que não pode ser transformada em números, ainda que, nela, são utilizados dados quantitativos para se realizar a interpretação.

Os dados de investigação do estudo foram obtidos por meio da implementação de um curso de qualificação docente para o ensino de programação de computadores por meio de metodologias ativas de aprendizagem e a teoria da carga cognitiva.

O referido curso sobre qualificação se instaurou em uma formação continuada para docentes das áreas de computação, informática e afins, sendo ofertado em duas edições, na modalidade de educação a distância por meio do Ambiente Virtual de Aprendizagem - AVA - pautado no Moodle. Compete registrar que a primeira edição do curso contou com uma carga horária total de 70 horas e aconteceu no ano de 2019. A segunda edição, por sua vez, teve uma carga horária total de 80 horas e ocorreu no ano de 2020.

Essa formação continuada se objetivava a qualificar os docentes participantes para o ensino de programação de computadores por meio do uso de metodologias ativas de aprendizagem e a teoria da carga cognitiva, a partir do desenvolvimento de reflexões sobre as variadas possibilidades de uma abordagem pedagógica respaldada nessas premissas.

Cabe destacar que, conforme já mencionado, o presente artigo corresponde a um pequeno recorte de um estudo exploratório relacionado a uma tese de doutorado, sendo que o curso de qualificação desenvolvido se constitui no produto educacional vinculado à pesquisa da tese. 
Ainda no que concerne à coleta de dados, pondera-se que estes foram obtidos por meio do recurso de questionários do Moodle, sendo dispostos logo no início do curso como um prérequisito para que o participante pudesse ter acesso aos demais conteúdos.

Nos questionários, foram coletados dados dos participantes quanto aos seguintes elementos:

- participação em atividades voltadas para a docência durante o ensino superior e a pós-graduação, bem como a percepção sobre a preparação fornecida nesses níveis para exercer a docência;

- percepção sobre a preparação em sua formação para ensinar programação e se sentiu ou teve dificuldades em aprender a programar;

- percepção sobre a importância de ter uma prática docente embasada por teorias de aprendizagem e metodologias de ensino/aprendizagem, bem como avaliar o conhecimento sobre elas;

- comparação das práticas pedagógicas, conteúdos, recursos e tecnologias, instrumentos e técnicas de avalição, atitudes de aprendizagem e perfil das turmas a que foi exposto durante o aprendizado de programação (enquanto aluno) e o que expõe seus alunos (enquanto docente);

- percepção sobre o alinhamento da prática docente com a educação contemporânea e com as necessidades e perspectivas dos estudantes atuais;

- autoavaliação prática como docente no ensino dos conteúdos introdutórios de programação e dos resultados de aprendizagem de seus alunos.

Por fim, compete salientar que o foco da análise dos dados coletados remete às comparações sobre a série de elementos destacados entre os participantes com ou sem formação pedagógica, os quais afirmaram ter ministrado, nos últimos cinco anos, alguma disciplina relacionada à programação de computadores.

\section{Caracterização da Amostra}

Inicialmente, compete registrar que o curso de qualificação já descrito, em suas duas edições, contou com um total de 178 participantes. Contudo, cabe destacar que 68,54\% $(n=122)$ desses participantes afirmaram ter ministrado alguma disciplina relacionada à programação nos últimos cinco anos, atendendo, assim, ao requisito definido para compor a amostra desta pesquisa.

Desse modo, a amostra deste estudo é composta por um total de 122 docentes, sendo: 43 participantes da primeira edição do curso ocorrida no ano de 2019 e 79 participantes da segunda edição realizada no ano de 2020. Ressalta-se que esses docentes serão caracterizados dentro de suas respectivas edições.

Assim, como padrão, serão utilizadas as seguintes nomenclaturas: Grupo 2019 para referenciar os 43 docentes e Grupo 2020 para os 79 docentes. No entanto, cumpre enfatizar que, na apresentação dos resultados, os docentes serão segmentados com formação pedagógica e sem formação pedagógica.

No Grupo 2019, 55,81\% (n=24) dos docentes declaram ser do gênero masculino e 44,19\% $(\mathrm{n}=19)$ do gênero feminino. No Grupo 2020, 55,70\% $(\mathrm{n}=44)$ dos docentes se declararam ser do gênero masculino, $43,04 \%(n=34)$ do gênero feminino e um participante $(1,27 \%)$ optou por não especificar seu gênero (Gráfico 1).

No que se refere às faixas etárias (Gráfico 2), as mais significativas no Grupo 2019 são: entre 41 e 50 anos, representando $37,21 \%(n=16)$; e entre 31 e 40 anos, representando $34,88 \%(n=15)$. No Grupo 2020, as faixas etárias mais significativas são: entre 41 e 50 anos, representando 36,71\% $(n=29)$; e entre 31 e 40 anos, representando $35,44 \%(n=28)$. 


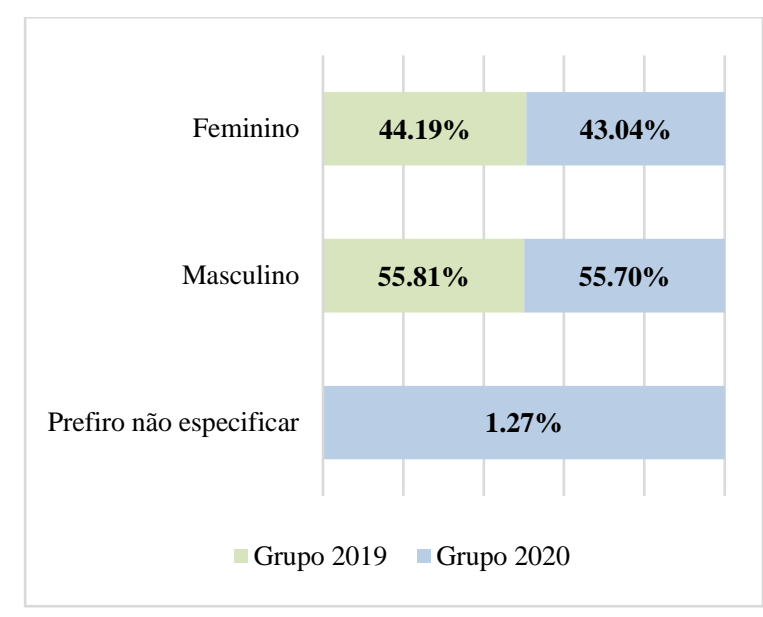

Gráfico 1: Gênero

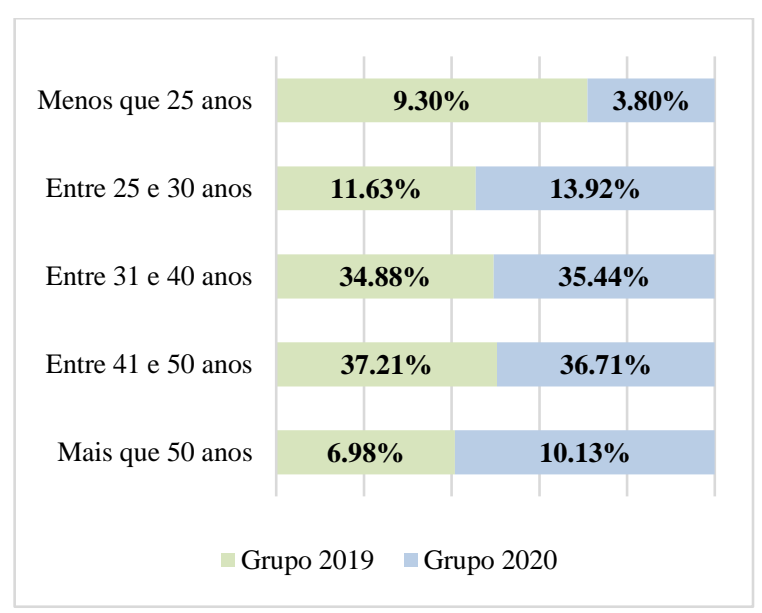

Gráfico 2: Faixa etária

Os participantes dos dois grupos estão distribuídos geograficamente em 22 das 27 unidades federativas do Brasil (Gráfico 3), sendo que, no Grupo 2019, aparecem 15 unidades da federação, destacando-se os estados do Rio Grande do Sul e São Paulo, com 20,93\% (n=9) docentes cada, Paraná, com 13,95\% ( $n=6)$, e Santa Catarina, com 9,30\% (n=4). No Grupo 2020, aparecem 20 unidades da federação, destacando-se os estados do Paraná, com 31,65\% $(n=25)$ docentes, São Paulo, com 15,19\% ( $\mathrm{n}=12)$, Distrito Federal, com 11,39\% ( $\mathrm{n}=9)$, e Rio Grande do Sul, com 7,59\% $(\mathrm{n}=6)$.

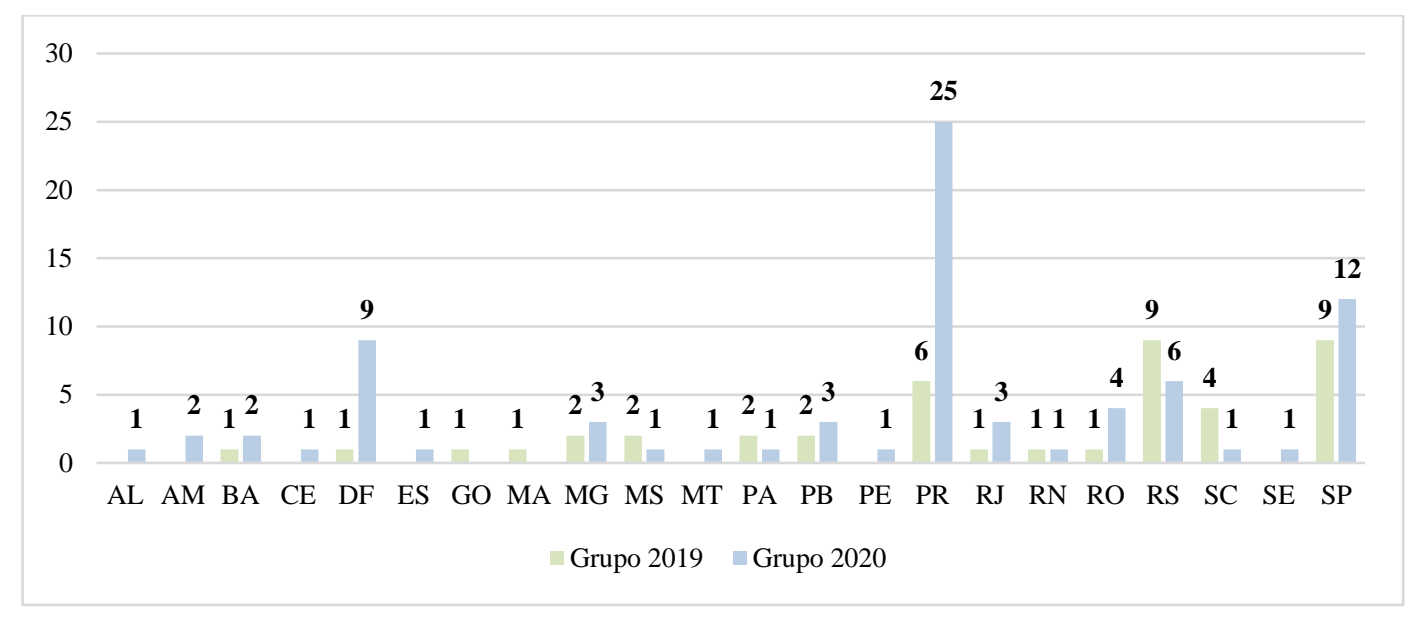

Gráfico 3: Distribuição geográfica dos participantes

A seguir, apresentam-se: a formação inicial (graduação) (Gráfico 4), o tipo de curso superior realizado (Gráfico 5) e o tempo de conclusão da graduação (Gráfico 6), dos dois grupos de docentes. 


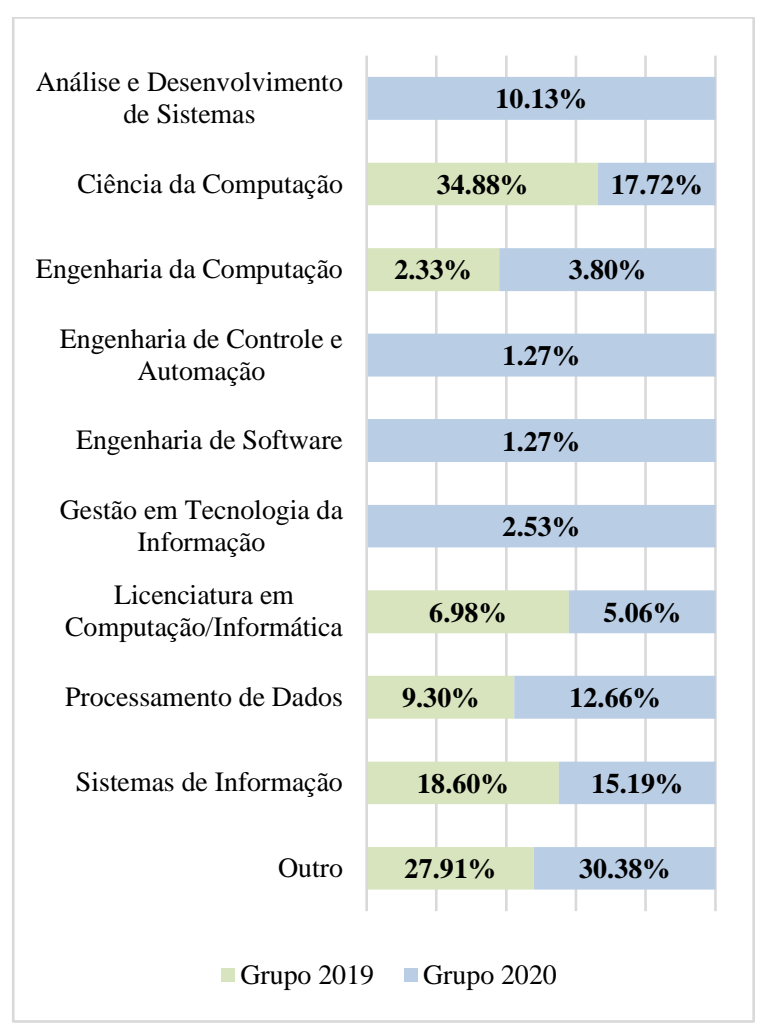

Gráfico 4: Formação inicial (Graduação)

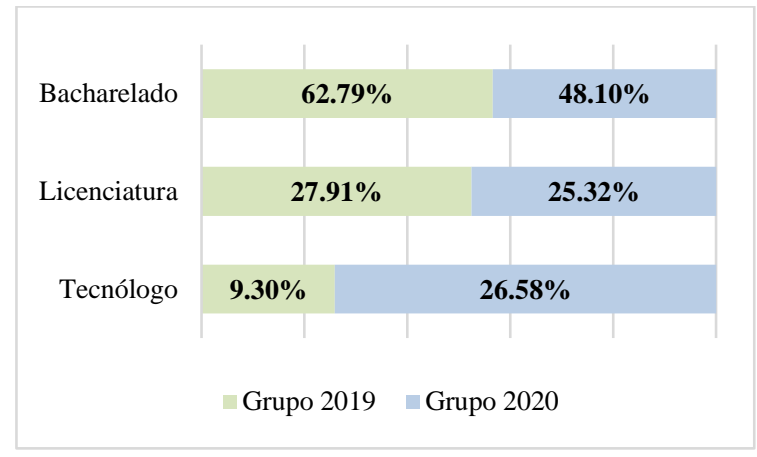

Gráfico 5: Tipo de curso superior

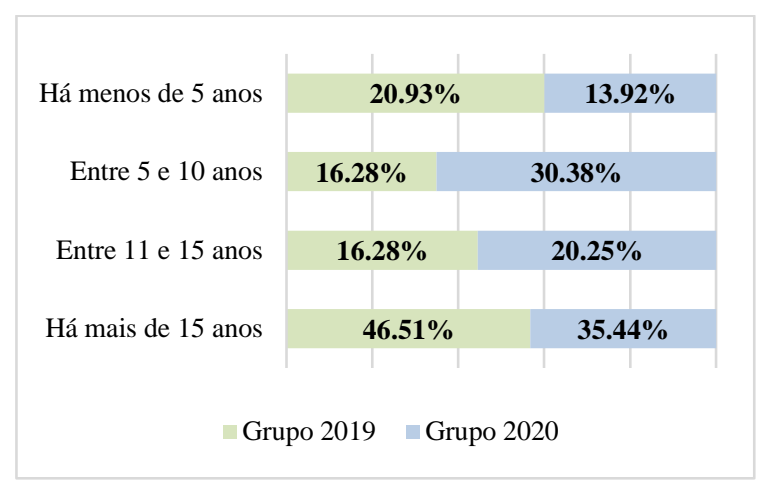

Gráfico 6: Tempo de conclusão da graduação

No que concerne à formação inicial (graduação) desses docentes (Gráfico 4), no Grupo 2019, destaca-se que 34,88\% (n=15) informaram ter cursado ciência da computação; por sua vez, no Grupo 2020, os cursos de ciência da computação, com 17,72\% (n=14), sistemas de informação, com $15,19 \%(n=12)$, e processamento de dados, com $12,66 \%(n=10)$, foram os mais elencados pelos participantes. Entretanto, convém observar que uma parcela significativa nos dois grupos afirmou ter realizado outro curso superior que não corresponde aos cursos tradicionais da área da computação. Essa parcela equivale a 27,91\% $(n=12)$, no Grupo 2019, e a 30,38\% $(n=24)$, no Grupo 2020.

Em relação ao tipo de curso superior (Gráfico 5), no Grupo 2019, 62,79\% (n=27) são oriundos de cursos de bacharelado, 27,91\% $(\mathrm{n}=12)$ de licenciatura e 9,30\% $(\mathrm{n}=4)$ de tecnologia; no Grupo 2020, 48,10\% $(n=38)$ de bacharelado, 26,58\% $(n=21)$ de tecnologia e 25,32\% (n=20) de licenciatura. No que diz respeito ao tempo de conclusão da graduação (Gráfico 6), no Grupo 2019, a parcela mais significativa, $46,51 \%(n=20)$, concluiu sua formação inicial há mais de 15 anos; no Grupo 2020, as parcelas mais significativas são há mais de 15 anos, 35,44\% $(\mathrm{n}=28)$, e entre 5 e 10 anos, 30,38\% $(n=24)$.

A seguir, expõem-se a maior titulação (Gráfico 7), a área do conhecimento da maior titulação (Gráfico 8) e o tempo de conclusão da maior titulação (Gráfico 9), dos dois grupos de docentes. 


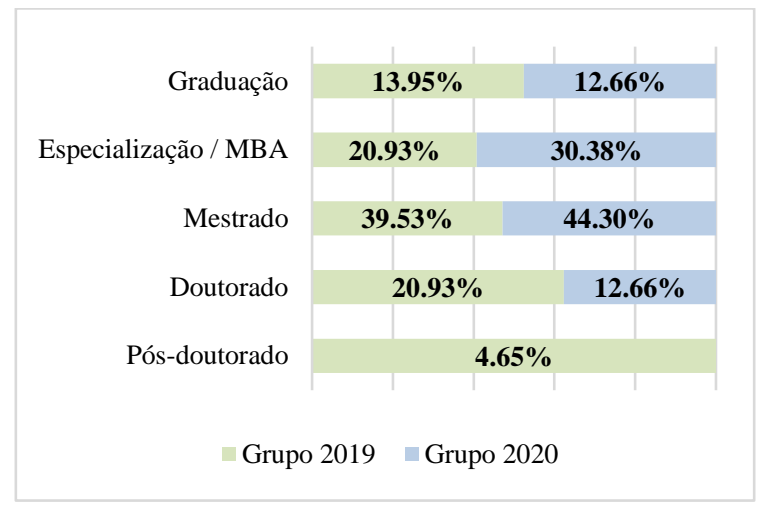

Gráfico 7: Maior titulação

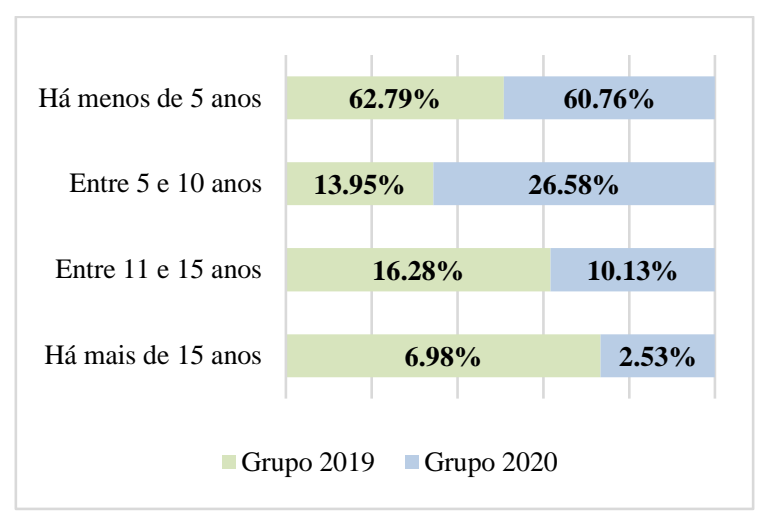

Gráfico 9: Tempo de conclusão da maior titulação

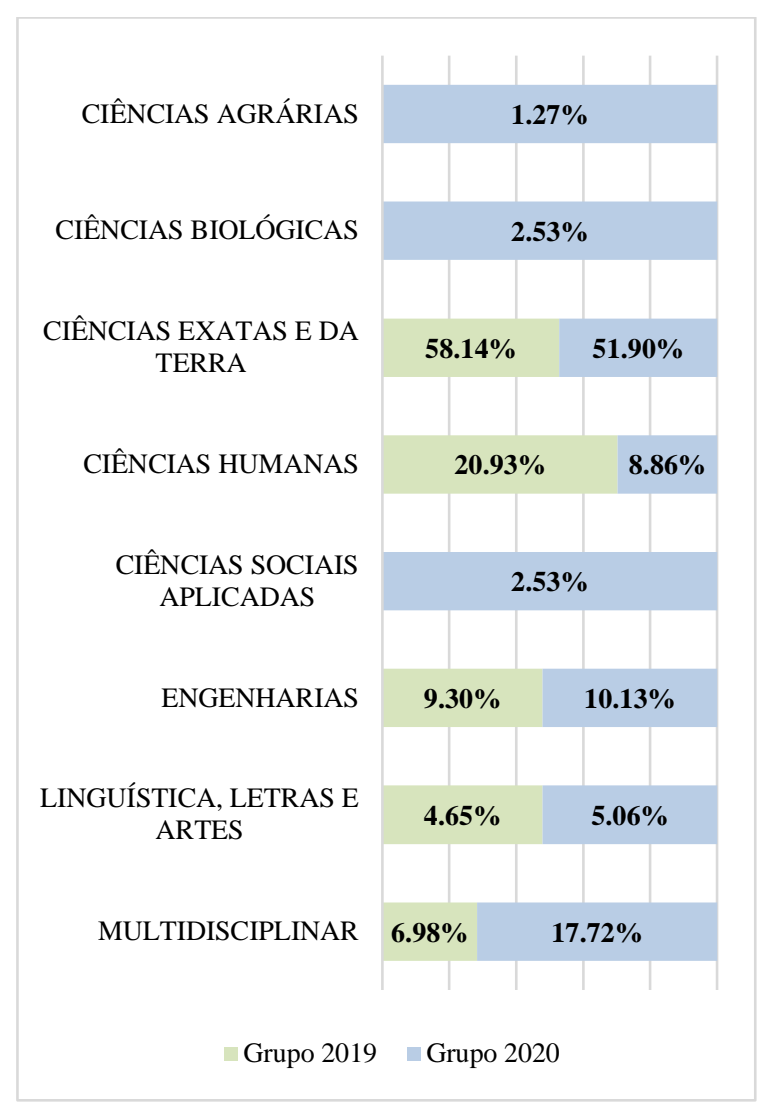

Gráfico 8: Área do conhecimento da maior titulação

No que tange à maior titulação (Gráfico 7), o Grupo 2019 é composto por: 39,53\% $(n=17)$ de docentes que têm como maior titulação Mestrado, Especialização/MBA e Doutorado 20,93\% $(n=9)$ cada, 13,95\% $(n=6)$ Graduação e 4,65\% $(n=2)$ Pós-Doutorado; já o Grupo 2020 é composto por: 44,30\% $(n=35)$ Mestrado, 30,38\% $(n=24)$ Especialização/MBA, Doutorado e Graduação $12,66 \%(\mathrm{n}=10)$ cada.

Referente à área do conhecimento da maior titulação (Gráfico 8) dos docentes presentes nos dois grupos, constata-se que a área Ciências Exatas e da Terra, a qual abarca os cursos de computação, corresponde à parcela mais significativa, sendo que, no Grupo 2019, ela equivale a $58,14 \%(\mathrm{n}=25)$ e, no Grupo 2020, a 51,90\% $(\mathrm{n}=41)$.

Ainda no que concerne à maior titulação desses docentes, especificamente há quanto tempo ela foi concluída (Gráfico 9), observa-se que, nos dois grupos, a parcela mais significativa concluiu há menos de 5 anos, já que, no Grupo 2019, essa parcela corresponde a $62,79 \%(n=27)$ e, no Grupo 2020, a 60,76\% (n=48).

A seguir, evidenciam-se o tempo de atuação como docente (Gráfico 10) e os tipos de instituição onde esses professores atuam (Gráfico 11), dos dois grupos de docentes. 


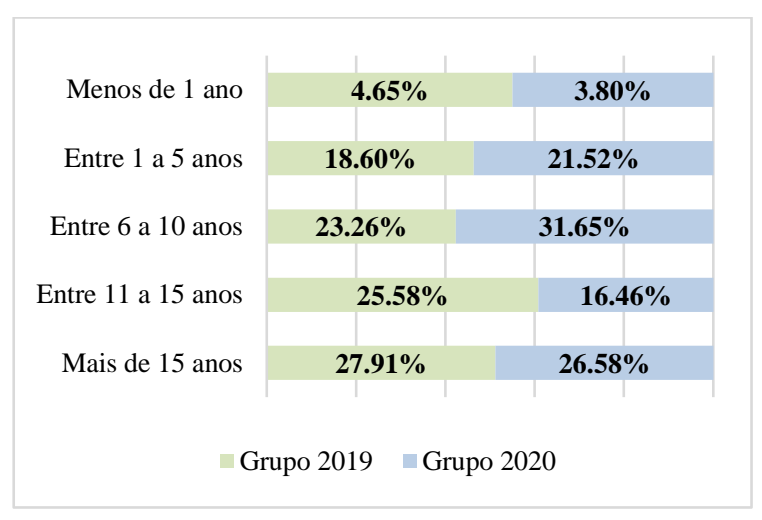

Gráfico 10: Tempo de atuação como docente

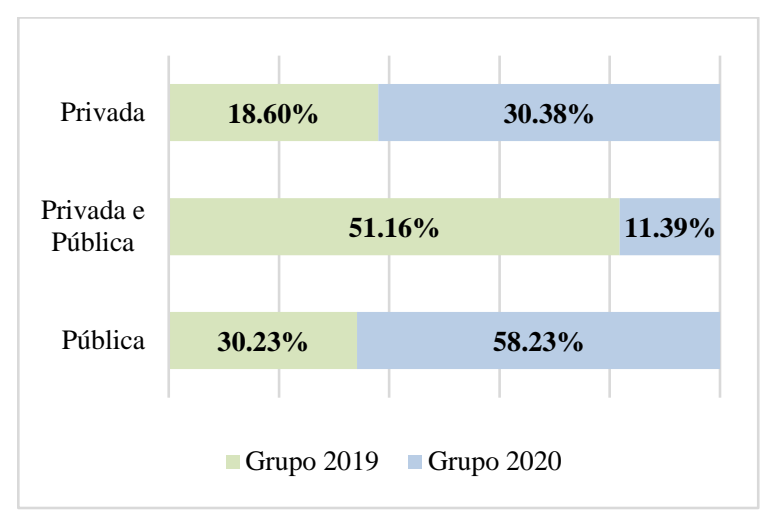

Gráfico 11: Tipos de instituição onde atuam

Em relação ao tempo de atuação como docente (Gráfico 10), no Grupo 2019, 27,91\% (n=12) dos docentes atuam há mais de 15 anos, 25,58\% $(\mathrm{n}=11)$ entre 11 a 15 anos, 23,26\% $(\mathrm{n}=10)$ entre 6 a 10 anos, $18,60 \%(n=8)$ entre 1 a 5 anos e 4,65\% $(n=2)$ há menos de 1 ano; no Grupo 2020, $31,65 \%(n=25)$ entre 6 a 10 anos, 26,58\% $(n=21)$ há mais de 15 anos, $21,52 \%(n=17)$ entre 1 a 5 anos, $16,46 \%(n=13)$ entre 11 a 15 anos e 3,80\% $(n=3)$ há menos de 1 ano.

No que se refere aos tipos de instituição onde esses professores atuam (Gráfico 11), no Grupo $2019,51,16 \%(\mathrm{n}=22)$ atuam em instituições privadas e públicas, 30,23\% $(\mathrm{n}=13)$ atuam somente em instituições públicas e 18,60\% $(\mathrm{n}=8)$ atuam somente em instituições privadas; no Grupo 2020, $58,23 \%(\mathrm{n}=46)$ atuam somente em instituições públicas, 30,38\% $(\mathrm{n}=24)$ somente em instituições privadas e $11,39 \%(n=9)$ em instituições privadas e públicas.

A seguir, apresentam-se as modalidades de ensino em que esses docentes atuam (Gráfico 12), níveis de ensino (Gráfico 13) e há quanto tempo lecionam as matérias concernentes à programação (Gráfico 14), dos dois grupos de docentes. 


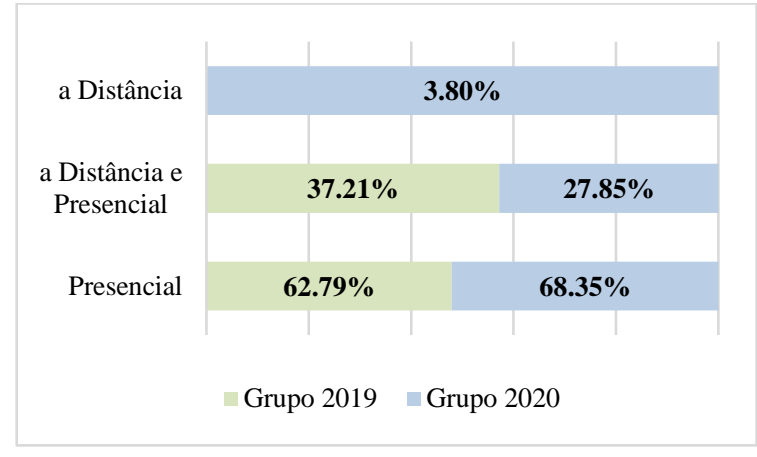

Gráfico 12: Modalidades de ensino em que atuam

\begin{tabular}{|r|r|r|}
\hline & \multicolumn{2}{|l|}{$\mid$} \\
\hline Menos de 1 ano & $\mathbf{2 3 . 2 6 \%}$ & $\mathbf{1 6 . 4 6 \%}$ \\
\hline Entre 1 a 5 anos & $\mathbf{2 3 . 2 6 \%}$ & \multicolumn{2}{|c|}{$\mathbf{4 1 . 7 7 \%}$} \\
\hline Entre 6 a 10 anos & $\mathbf{2 5 . 5 8 \%}$ & $\mathbf{1 7 . 7 2 \%}$ \\
\hline Entre 11 a 15 anos & $\mathbf{1 1 . 6 3 \%}$ & $\mathbf{1 2 . 6 6 \%}$ \\
\hline Mais de 15 anos & $\mathbf{1 6 . 2 8 \%}$ & $\mathbf{1 1 . 3 9 \%}$ \\
\hline & & \\
\hline
\end{tabular}

Gráfico 14: Há quanto tempo lecionam matérias relacionadas à programação

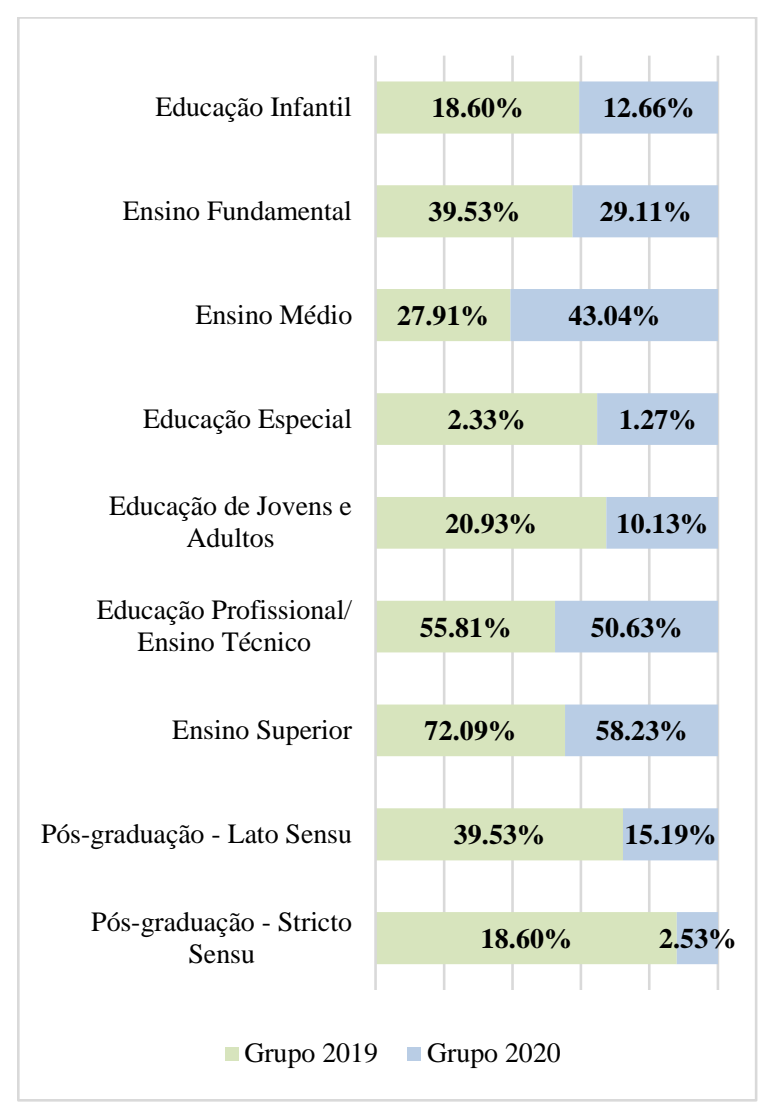

Gráfico 13: Níveis de ensino em que atuam

No que compete às modalidades de ensino em que esses docentes atuam (Gráfico 12), destacam-se, em ambos os grupos, o ensino presencial, que corresponde a $62,79 \%(n=27)$ e 68,35\% ( $\mathrm{n}=54)$, no Grupo 2019 e Grupo 2020, respectivamente, seguido das modalidades a distância e presencial, com 37,21\% ( $\mathrm{n}=16)$ no Grupo 2019 e 27,85\% (n=22) no Grupo 2020.

Sobre os níveis de ensino em que esses docentes atuam (Gráfico 13), salientam-se, em ambos os grupos, o ensino superior, que corresponde a 72,09\% $(n=31)$ no Grupo 2019 e a 58,23\% $(n=46)$ no Grupo 2020, e a educação profissional/ensino técnico, com 55,81\% $(\mathrm{n}=24)$ no grupo 2019 e 50,63\% (n=40) no Grupo 2020.

Em relação há quanto tempo esses docentes lecionam as matérias concernentes à programação (Gráfico 14), expressam-se as seguintes faixas: entre 1 a 5 anos, com 23,26\% ( $\mathrm{n}=10)$, e 41,77\% (n=33); entre 6 a 10 anos, com 25,58\% $(n=11)$, e $17,72 \%(n=14)$, e menos de 1 ano, com 23,26\% (n=10), e 16,46\% ( $\mathrm{n}=13)$ nos Grupos 2019 e Grupo 2020, respectivamente.

$\mathrm{O}$ último item a ser apresentado nessa caracterização da amostra se refere à formação pedagógica (licenciatura ou equivalente) (Gráfico 15). 


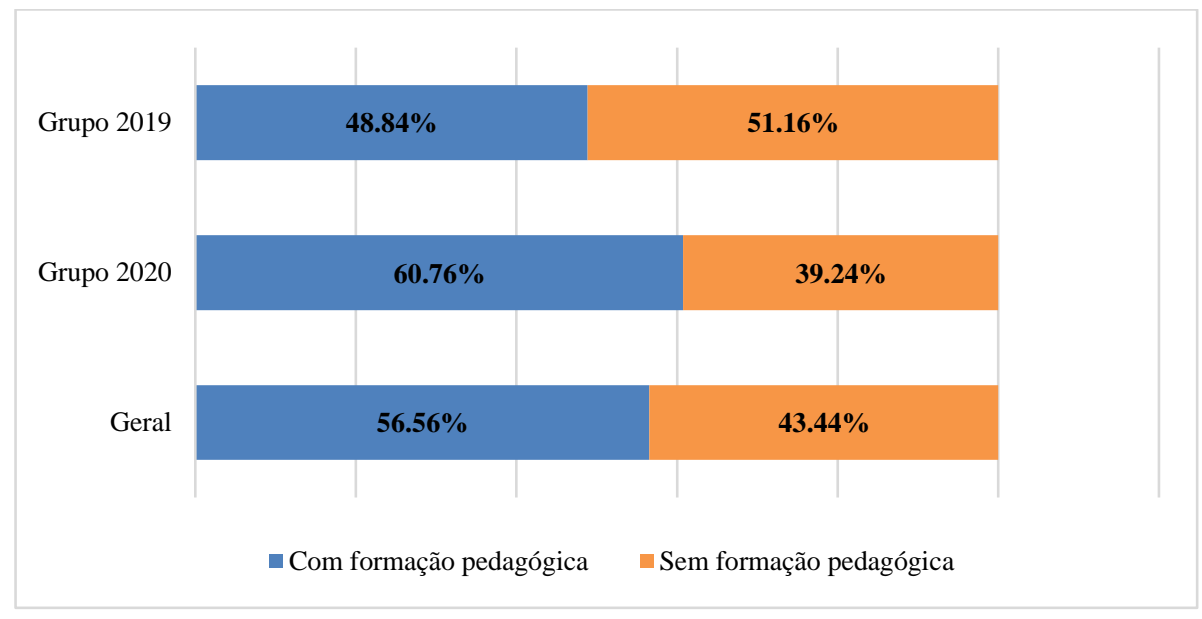

Gráfico 15: Formação pedagógica (Licenciatura ou equivalente)

A respeito da formação pedagógica (licenciatura ou equivalente), como pode ser observado no Gráfico 15, 51,16\% (n=22) dos docentes do Grupo 2019 afirmaram não possuir formação pedagógica, enquanto 48,84\% $(n=21)$ afirmaram possuir; no Grupo $2020,60,76 \%(n=48)$ afirmaram possuir formação pedagógica e 39,24\% $(n=31)$ afirmaram não possuir.

\section{Resultados: Análise e Discussões}

Conforme exposto no Gráfico 15, na seção anterior, a amostra desta pesquisa é composta por um total de 122 docentes, sendo que $56,56 \%(n=69)$ possuem formação pedagógica, enquanto $43,44 \%$ $(n=53)$ não possuem. A esses docentes, inicialmente, foi questionado se eles participaram de atividades voltadas para a docência durante o ensino superior (Gráfico 16) e se consideravam que tal nível de ensino possibilitou uma preparação para exercer a docência (Gráfico 17).

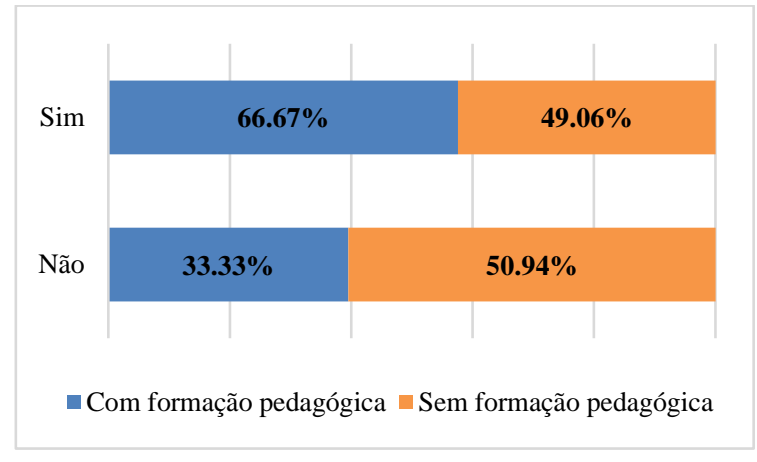

Gráfico 16: Participação em atividades voltadas para a docência durante o ensino superior

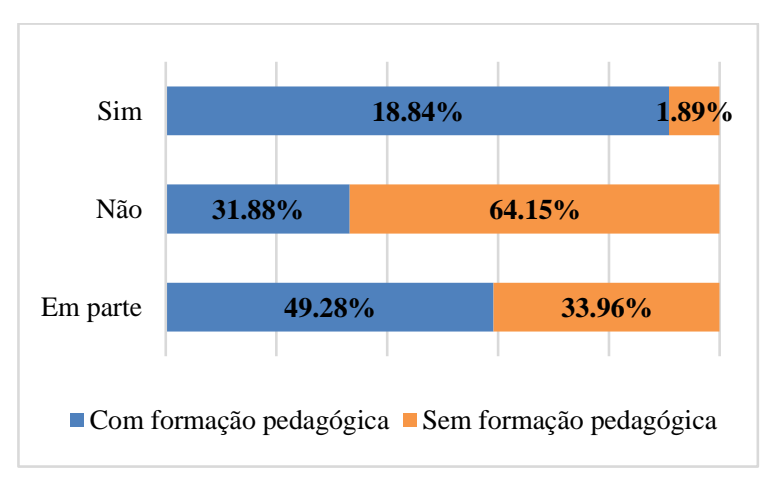

Gráfico 17: Percepção sobre a preparação fornecida no ensino superior para exercer a docência

No que se refere à participação em atividades voltadas para a docência durante o ensino superior (Gráfico 16), 66,67\% $(\mathrm{n}=46)$ dos docentes que possuem formação pedagógica afirmaram ter participado dessas atividades e 33,33\% $(n=23)$ afirmaram não ter participado; em relação aos docentes que não possuem formação pedagógica, $50,94 \%(\mathrm{n}=27)$ afirmaram não ter participado e $49,06 \%(n=26)$ afirmaram ter participado. 
Quanto à percepção sobre a preparação fornecida no ensino superior para exercer a docência (Gráfico 17), 49,28\% ( $\mathrm{n}=34)$ dos docentes que possuem formação pedagógica consideraram que o ensino superior possibilitou um preparo em parte para a exercer a docência, $31,88 \%(\mathrm{n}=22)$ consideraram que o ensino superior não possibilitou o preparo e $18,84 \%(n=13)$ consideraram que sim; por outro lado, 64,15\% $(n=34)$ dos docentes que não possuem formação pedagógica consideraram que o ensino superior não os preparou para exercer a docência, $33,96 \%(n=18)$ ponderaram que houve um preparo em parte e um docente considerou que sim $(1,89 \%)$.

Em relação ao primeiro questionamento, compete destacar dois pontos: o primeiro se refere ao número de docentes sem formação pedagógica que participaram de atividades voltadas para a docência durante a graduação: 49,06\% $(\mathrm{n}=26)$; já o segundo concerne ao número também elevado de docentes, mas com formação pedagógica e que afirmaram não ter participado de atividades voltadas para a docência $33,33 \%(n=23)$.

No segundo questionamento, destaca-se que, ainda em um percentual baixo, $18,84 \%(n=13)$, os docentes que possuem formação pedagógica têm uma percepção positiva muito acima da preparação do ensino superior para exercer a docência, em comparação aos docentes que não possuem essa formação: $1,89 \%(\mathrm{n}=1)$.

Assim, observa-se que os docentes que possuem formação pedagógica participaram mais de atividades direcionadas ao exercício do magistério durante a graduação, bem como possuem uma percepção positiva muito acima da preparação do ensino superior para exercer a docência, quando comparados aos docentes que não possuem essa formação. De certa forma, esses resultados eram esperados, tendo em vista que o exercício da docência é um dos principais focos de cursos de licenciatura. Em contrapartida, cursos superiores de bacharelado e tecnologia não possuem esse enfoque.

Aos docentes que possuíam curso em nível de pós-graduação (lato ou stricto senso), foram reproduzidos esses mesmos questionamentos iniciais, os quais foram respondidos por 106 participantes, sendo que 55,66\% $(n=59)$ possuíam formação pedagógica, enquanto $44,34 \%(n=47)$ não possuíam.

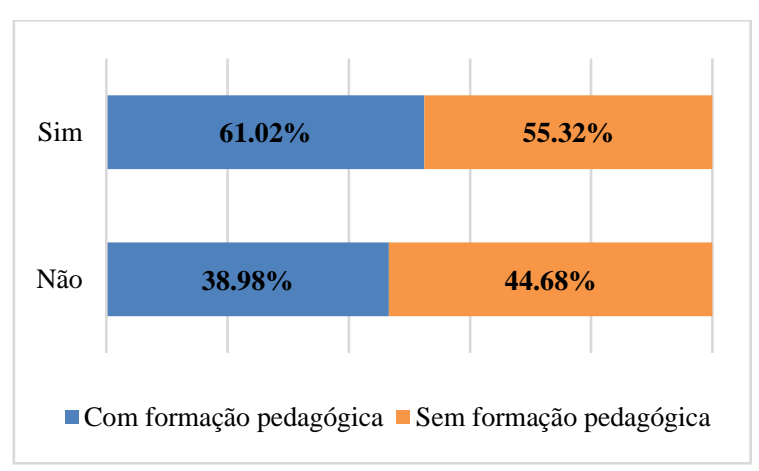

Gráfico 18: Participação em atividades voltadas para a docência durante a pós-graduação

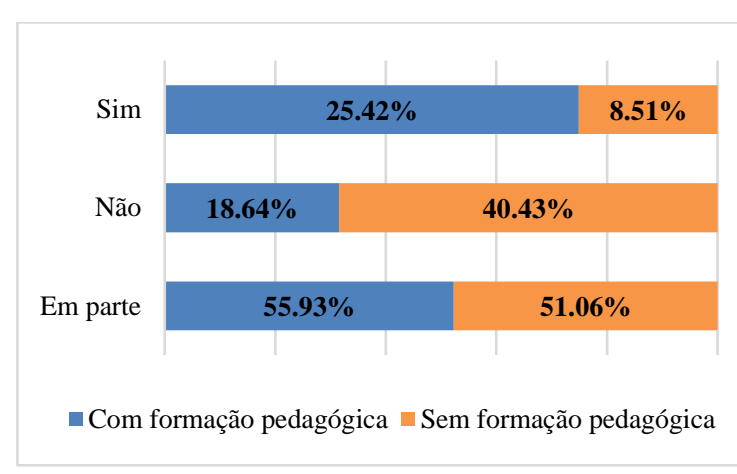

Gráfico 19: Percepção sobre a preparação fornecida durante a pós-graduação para exercer a docência

Como pode ser observado no Gráfico $18,61,02 \%(n=36)$ dos docentes que possuem formação pedagógica afirmaram ter participado de atividades voltadas para a docência durante a pósgraduação, enquanto 38,98\% $(\mathrm{n}=23)$ afirmaram que não participaram; já nos docentes que não possuem formação pedagógica, notamos que $55,32 \%(\mathrm{n}=26)$ afirmaram ter participado e 44,68\% $(\mathrm{n}=21)$ afirmaram não ter participado. 
Em relação à percepção desses professores, isto é, sobre a pós-graduação preparar para exercer a docência (Gráfico 19), entre os docentes que possuem formação pedagógica, 55,93\% $(n=33)$ consideram em parte, 25,42\% $(n=15)$ consideraram que sim e $18,64 \% \quad(n=11)$ consideraram que não; por sua vez, entre os docentes que não possuem formação pedagógica, consideram em parte $51,06 \%(n=24), 40,43 \%(n=19)$ consideraram que não e $8,51 \%(n=4)$ consideraram que sim.

No que concerne ao primeiro questionamento, percebe-se que os docentes que possuem formação pedagógica participaram menos de atividades voltadas para o exercício da docência durante a pós-graduação $(61,02 \%)$ quando em comparação ao ensino superior $(66,67 \%)$. Por outro lado, constata-se um aumento na participação em atividades voltadas para a docência durante a pós-graduação, em conformidade ao ensino superior entre os docentes que não possuem formação pedagógica. Na pós-graduação, esses professores correspondem a 55,32\%, enquanto, no ensino superior, correspondem a $49,06 \%$.

Ademais, salienta-se que a percepção dos docentes com ou sem formação pedagógica teve um aumento expressivo, comparativamente ao ensino superior: entre os docentes que possuem formação pedagógica, registrou-se um aumento de $18,84 \%$ no ensino superior para $25,42 \%$; entre os docentes sem formação, verificou-se o aumento de 1,89\% para 8,51\%. Dessa forma, com base na amostragem, pode-se presumir que, mesmo a pós-graduação não se objetivando a formar docentes, esse nível de ensino pode contribuir, de algum modo, para a preparação ao exercício do magistério.

Diante do exposto, os docentes foram questionados se consideram que sua formação, de um modo geral, possibilitou o preparo para ensinar programação (Gráfico 20) e se sentiram ou tiveram dificuldades em aprender a programar (Gráfico 21).

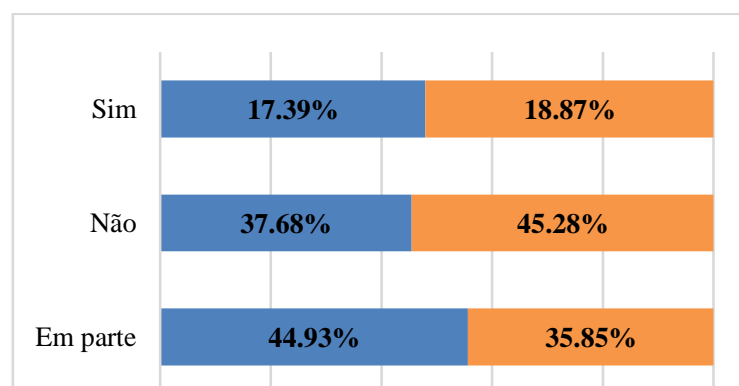

• Com formação pedagógica $\varpi$ Sem formação pedagógica

Gráfico 20: Considera que sua formação o preparou para ensinar programação

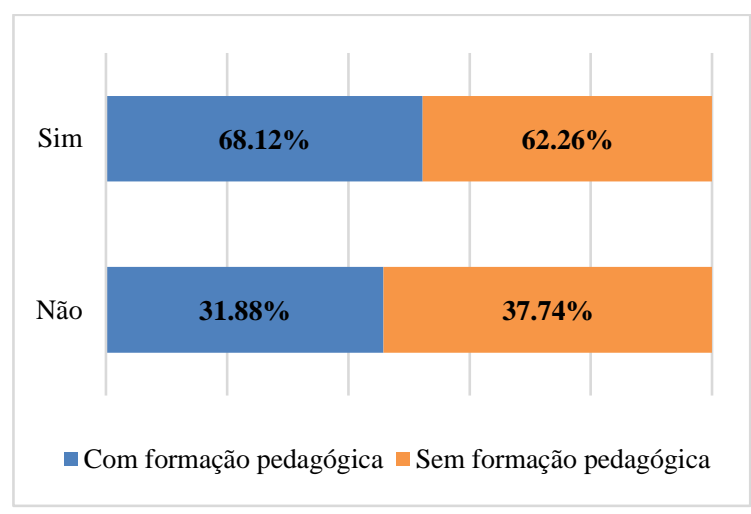

Gráfico 21: Sentiu ou teve dificuldades em aprender a programar

Conforme pode ser notado no Gráfico 20, referente à percepção desses docentes sobre a sua formação preparar para ensinar programação, no grupo de docentes que possuem formação pedagógica, 44,93\% $(\mathrm{n}=31)$ responderam em parte, 37,68\% $(\mathrm{n}=26)$ responderam não e 17,39\% $(n=12)$ responderam sim; no grupo de docentes que não possuem formação pedagógica, 45,28\% $(n=24)$ responderam não, 35,85\% $(n=19)$ responderam em parte e $18,87 \%(n=10)$ responderam sim.

No que tange ao exposto, vale ressaltar que a percepção de que a sua formação não preparou para ensinar programação é superior no grupo de docentes sem formação pedagógica. Nesse sentido, compete ponderar que, conforme a caracterização da amostra, uma parcela significativa dos docentes afirmou ter realizado outro curso superior que não corresponde aos cursos 
tradicionais da área da computação (Gráfico 4). Nessa direção, Kretzer et al. (2020) apresentam um movimento para implementar o ensino de computação em maior escala e, dessa forma, recrutam-se docentes, mesmo que formados em outras áreas, para ensinar computação e, consequentemente, programação.

Em relação ao questionamento sobre sentir ou ter dificuldades durante o aprendizado de programação (Gráfico 21), no grupo de docentes que possuem formação pedagógica, 68,12\% $(\mathrm{n}=47)$ responderam que $\operatorname{sim}$, enquanto $31,88 \%(\mathrm{n}=22)$ responderam que não; no grupo de docentes sem formação pedagógica, 62,26\% $(n=33)$ responderam que sim e $37,74 \%(n=20)$ responderam não.

Ainda quanto ao referido questionamento, destacam-se os elevados percentuais dos docentes que afirmaram sentir ou ter dificuldades durante o aprendizado de programação em ambos os grupos, sendo esse percentual superior no grupo de docentes que possuem formação pedagógica $(68,12 \%)$, em comparação ao grupo de docentes sem formação pedagógica $(62,26 \%)$.

Além disso, convém explanar que, em ambos os grupos, o índice apontado pela amostra, ou seja, de docentes que sentiram ou tiveram dificuldades em aprender a programar, corresponde a mais que o dobro do índice de insucesso em disciplinas introdutórias de programação, que, conforme evidenciado pelos estudos de Bennedsen e Caspersen (2007), Watson e Li (2014), Bosse e Gerosa (2015) e Simon et al. (2019), gira em torno de 30\%. No entanto, é pertinente registrar que o referido questionamento, tratando-se apenas da percepção desses docentes sobre suas dificuldades no aprendizado de programação, não concerne aos índices de reprovação deles.

Na sequência, no Gráfico 22, são apresentadas as respostas sobre a percepção dos professores quanto à importância de embasar a prática docente em teorias de aprendizagem. No Gráfico 23, evidencia-se como os professores avaliam seus conhecimentos sobre as teorias de aprendizagem.

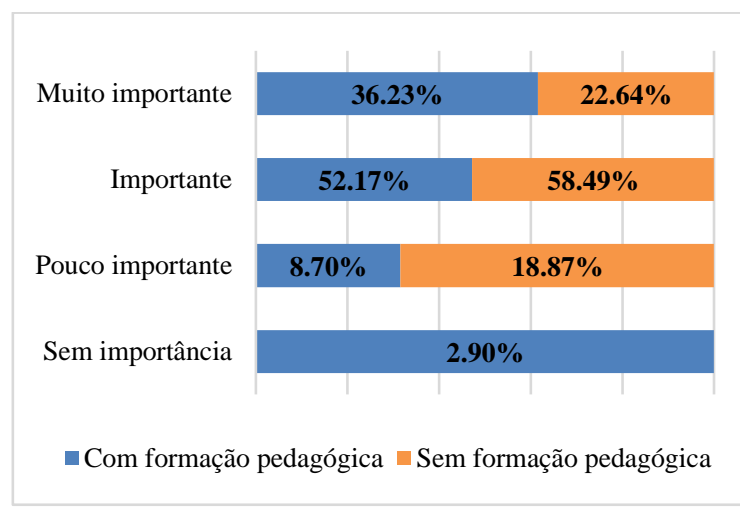

Gráfico 22: Percepção sobre a importância de ter uma prática professoral embasada por Teorias de Aprendizagem

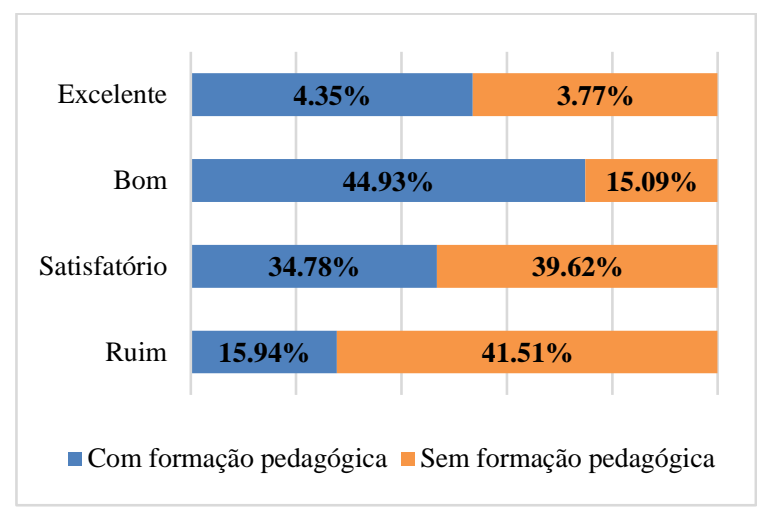

Gráfico 23: Avaliação dos conhecimentos sobre Teorias de Aprendizagem

De uma maneira geral, como é possível averiguar no Gráfico 22, tanto os docentes que possuem formação pedagógica quanto aqueles que não possuem consideram como importante $(58,49 \%(n=31)$ docentes sem formação e $52,17 \%(n=36)$ com formação) ou muito importante $(36,23 \%(n=25)$ docentes com formação e $22,64 \%(n=12)$ sem formação) ter uma prática professoral embasada em teorias de aprendizagem.

No que se refere à avaliação dos docentes sobre seus conhecimentos quanto às teorias de aprendizagem (Gráfico 23), observa-se que 44,93\% $(n=31)$ dos docentes que possuem formação pedagógica avaliam seus conhecimentos sobre a referida temática como bom, enquanto 34,78\% $(n=24)$ avaliam como satisfatório, $15,94 \%(n=11)$ avaliam como ruim e 4,35\% $(n=3)$ como 
excelente. Por outro lado, 41,51\% $(\mathrm{n}=22)$ dos docentes sem formação pedagógica avaliam seus conhecimentos sobre teorias de aprendizagem como ruim, 39,62\% $(\mathrm{n}=21)$ como satisfatório, $15,09 \%(n=8)$ como bom e $3,77 \%(n=2)$ como excelente.

Desse modo, assevera-se que, apesar de ambos os grupos de docentes considerarem importante ter uma prática professoral embasada por teorias de aprendizagem, de uma forma geral, os docentes que possuem formação pedagógica se avaliam como tendo um conhecimento bom ou satisfatório sobre a referida temática, enquanto os docentes sem formação pedagógica se avaliam como tendo um conhecimento ruim ou satisfatório.

Na mesma direção dos dois últimos questionamentos, indagou-se a esses docentes sobre sua percepção quanto à importância de ter uma prática professoral embasada por metodologias de ensino/aprendizagem (Gráfico 24) e como avaliam seus conhecimentos sobre elas (Gráfico 25).

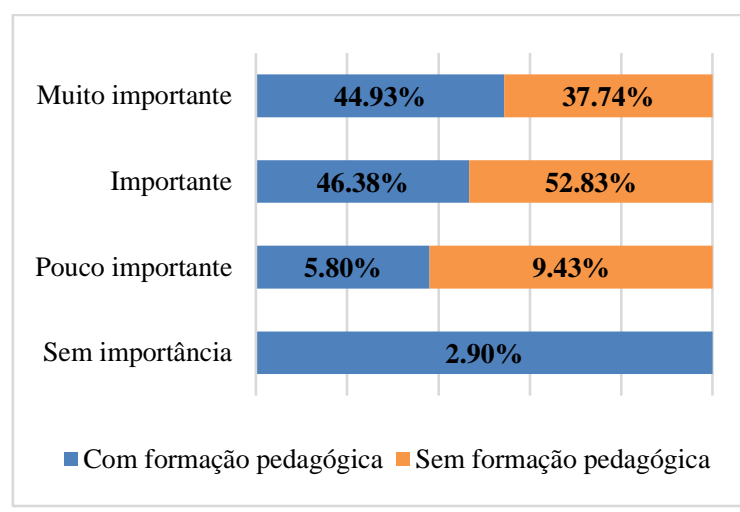

Gráfico 24: Percepção sobre a importância de ter uma prática professoral embasada por metodologias de ensino/aprendizagem

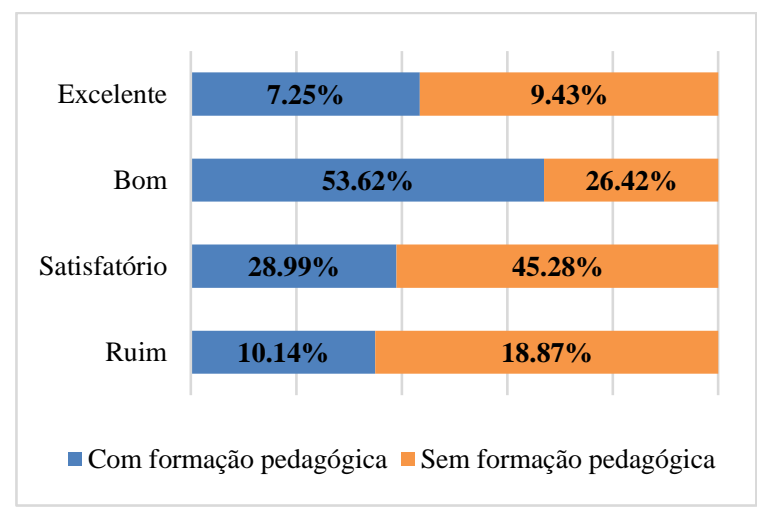

Gráfico 25: Avaliação dos conhecimentos sobre metodologias de ensino/aprendizagem

Como pode ser verificado no Gráfico 24, apesar da variação dos percentuais, as respostas dos docentes sobre a importância de ter uma prática professoral embasada por metodologias de ensino/aprendizagem são similares às apresentadas anteriormente para a importância de ter uma prática professoral embasada por teorias de aprendizagem. À vista disso, atesta-se que, de um modo geral, os dois grupos consideram importante ou muito importante ter uma prática alicerçada às metodologias de ensino/aprendizagem.

No que se refere aos conhecimentos dos docentes sobre metodologias de ensino/aprendizagem (Gráfico 25), destaca-se, também, que, similarmente aos conhecimentos sobre teorias de aprendizagem, os docentes que possuem formação pedagógica avaliam seus conhecimentos como bom, em um percentual significativamente maior do que os docentes que não possuem essa formação.

Além disso, convém salientar que os docentes que não possuem formação avaliaram seus conhecimentos sobre metodologias de ensino/aprendizagem como satisfatório 45,28\% $(n=24)$ e bom 26,42 ( $\mathrm{n}=14)$, diferentemente da avaliação realizada sobre as teorias de aprendizagem, em que avaliaram como ruim ou satisfatório. Entretanto, deve-se ressaltar que, enquanto as diversas metodologias de ensino/aprendizagem servem como modelos mais ou menos flexíveis para a condução do processo de ensino/aprendizagem, as teorias de aprendizagem tentam explicar como efetivamente a aprendizagem funciona e porque funciona. Destarte, os conhecimentos sobre a aprendizagem são essenciais, a fim de que se possa, por meio deles, nortear o processo.

Na sequência, são apresentadas as respostas dos docentes quanto à comparação das práticas pedagógicas, conteúdos, recursos e tecnologias, instrumentos e técnicas avaliativas, além das 
atitudes de aprendizagem e perfil dos estudantes e turmas a que esses docentes foram expostos (enquanto estudantes) e que expõem (como professores), sendo essa comparação realizada pelos docentes com formação pedagógica, no Gráfico 26, e sem essa formação, no Gráfico 27.

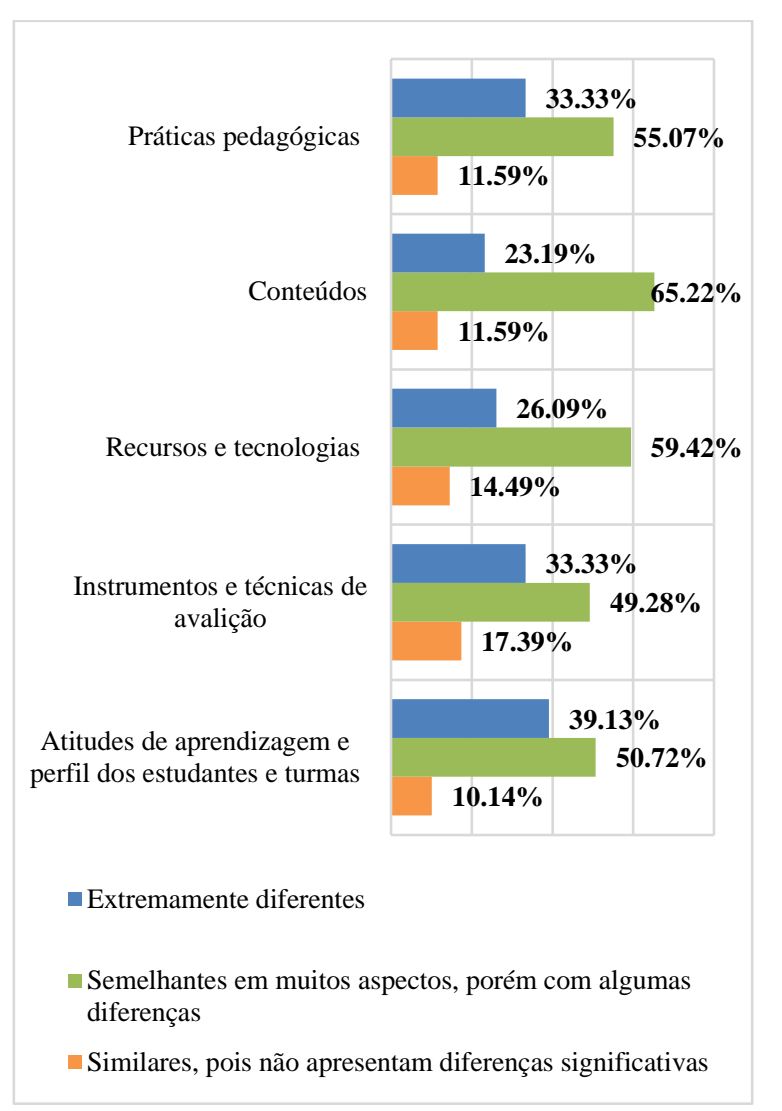

Gráfico 26: Docentes com formação pedagógica comparação de elementos quando expostos (enquanto estudantes) e que expõem (como professores)

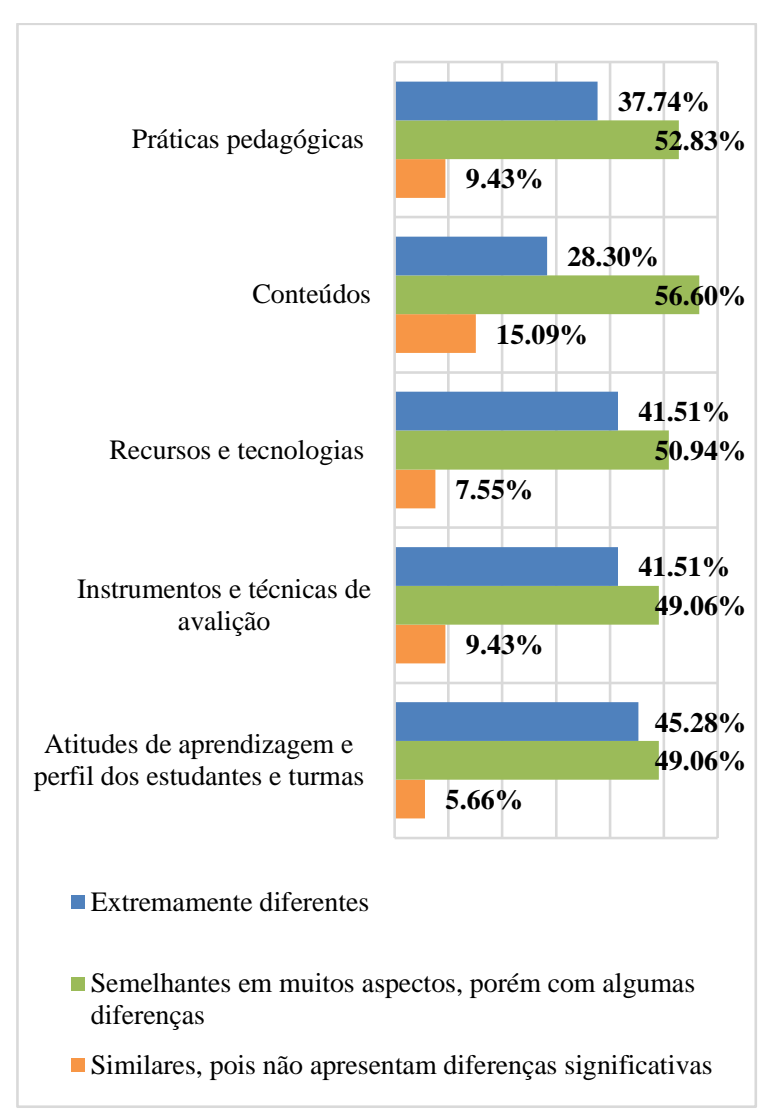

Gráfico 27: Docentes sem formação pedagógica comparação de elementos quando expostos (enquanto estudantes) e que expõem (como professores)

Inicialmente, realça-se que, conforme pode ser observado no Gráfico 26, que trata da comparação da série de elementos pelos docentes com formação pedagógica, e no Gráfico 27 , realizado pelos docentes sem essa formação, de uma maneira abrangente, em ambos os grupos, todos os elementos tratados foram apontados em maior proporção como sendo semelhantes em muitos aspectos, porém com algumas diferenças.

Assim, observa-se que tanto docentes com formação pedagógica como aqueles que não possuem essa formação consideram que as práticas pedagógicas, conteúdos, recursos e tecnologias, instrumentos e técnicas avaliativas, além das atitudes de aprendizagem e perfil dos estudantes e turmas a que foram expostos enquanto eram estudantes são semelhantes em muitos aspectos, porém com algumas diferenças quando, como docentes, expõem seus alunos.

Por conseguinte, se essa série de elementos pode ser considerada semelhante, verifica-se que, dentro da amostra, conforme pode ser observado em sua caracterização (Gráfico 6), conta-se com $39,34 \%(n=48)$ de docentes que concluíram a graduação há mais de 15 anos, 18,85\% $(n=23)$ que concluíram entre 11 e 15 anos e outros $25,41 \%(n=31)$ que concluíram entre 5 e 10 anos. Assim, pode-se conjecturar que os índices de insucesso em disciplinas introdutórias de programação estão diretamente relacionados à maneira com que continuamos a replicar no processo de ensino/aprendizagem de programação. Isso faz com que pouco se avance para se reverter o cenário. 
Além disso, faz-se necessário considerar que mais de 60\% desses docentes, em ambos os grupos, apontaram sentir ou ter dificuldades para aprender a programar (Gráfico 21) e se eles consideram que são semelhantes as práticas pedagógicas, os conteúdos, os recursos e as tecnologias, instrumentos e técnicas avaliativas, sobretudo as atitudes de aprendizagem e perfil dos estudantes e turmas. De certa forma, mais de $60 \%$ de seus estudantes irão sentir ou ter dificuldades em aprender a programar.

Todavia, convém destacar que as atitudes de aprendizagem e perfil dos estudantes e turmas, embora haja a consideração em maior parte de ambos os grupos como semelhante, é também o elemento mais apontado como extremamente diferente, sendo 39,13\% $(n=27)$ correspondentes aos docentes com formação pedagógica e 45,28\% $(n=24)$ aos docentes sem formação. Ademais, por mais que as atitudes de aprendizagem e perfil dos estudantes e turmas possam ser consideradas semelhantes, é perceptível que os educandos presentes no sistema formal de educação tenham expectativas em relação ao processo de ensino/aprendizagem, bem como de sua própria formação e desenvolvimento, muito diferentes de gerações anteriores.

Ao se pautar nessa ótica, no Gráfico 28, são apresentadas as repostas dos docentes que possuem formação pedagógica e, no Gráfico 29, evidenciam-se as respostas dos que não possuem formação quanto à percepção deles sobre o alinhamento de suas práticas com a educação contemporânea e as necessidades e perspectivas dos estudantes.

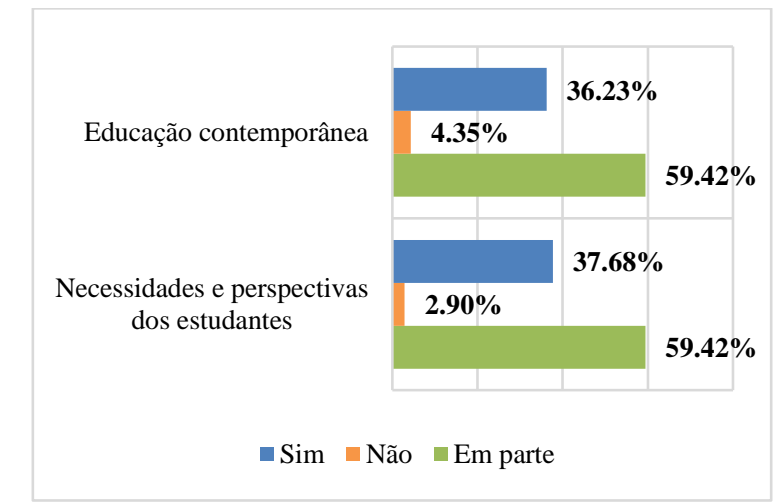

Gráfico 28: Docentes com formação pedagógica alinhamento da prática

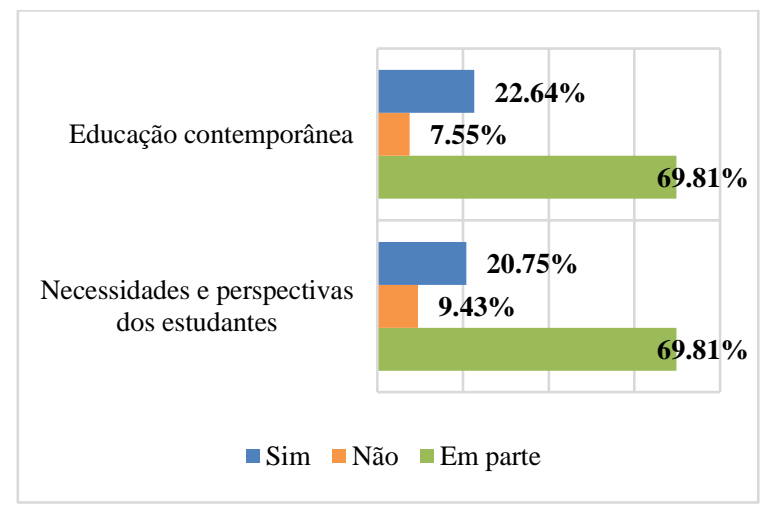

Gráfico 29: Docentes sem formação pedagógica alinhamento da prática

Com base nos resultados expostos no Gráfico 28 e no Gráfico 29, nota-se que, de um modo geral, tanto o grupo de docentes que possuem formação pedagógica quanto os que não possuem avaliam que sua prática docente está alinhada, em parte, com a educação contemporânea, bem como com as necessidades e perspectivas dos estudantes. Nessa acepção, o alinhamento em parte com esses elementos indicados pelos docentes corrobora com a comparação de diversos elementos realizada pelos professores, ao apontarem a semelhança entre o processo de ensino/aprendizagem que receberam enquanto eram estudantes e que fornecem aos seus alunos, assim como as análises efetuadas.

Ainda no que diz respeito à percepção do alinhamento de suas práticas com a educação contemporânea e as necessidades e perspectivas dos estudantes, observa-se que o grupo de docentes que possui formação pedagógica expressa uma percepção mais positiva referente a esses alinhamentos do que o grupo de docentes sem formação.

O último resultado a ser apresentado concerne à autoavaliação da prática como docente no ensino e dos resultados de aprendizagem de seus alunos em programação (Gráfico 30 e Gráfico $31)$. 


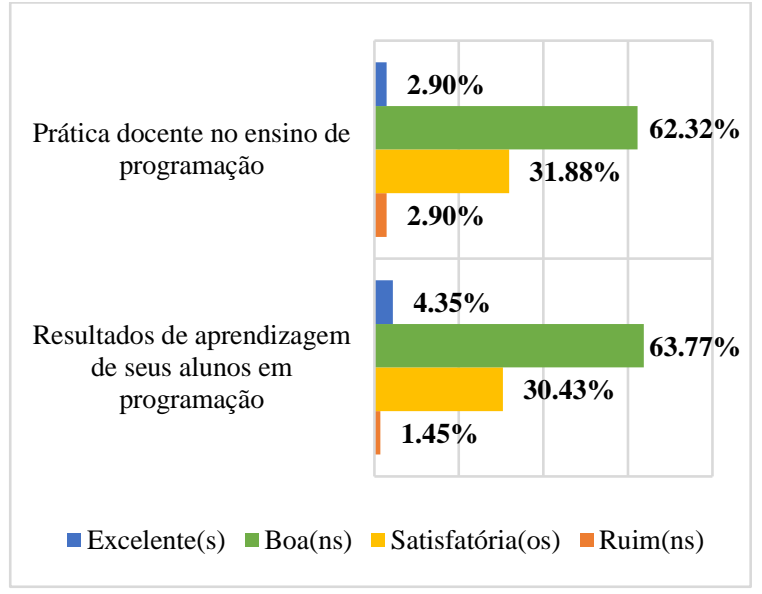

Gráfico 30: Docentes com formação pedagógica autoavaliação da prática como docente e dos resultados de aprendizagem dos alunos em programação

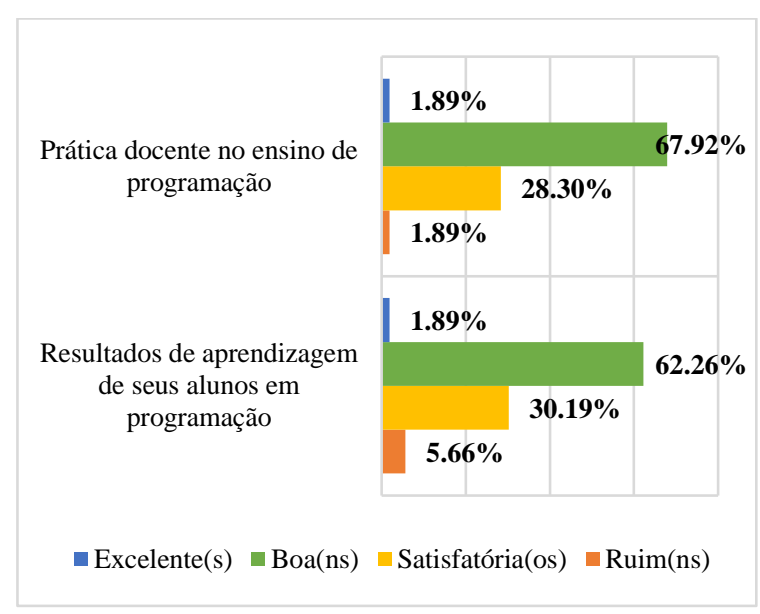

Gráfico 31: Docentes sem formação pedagógica autoavaliação da prática como docente e dos resultados de aprendizagem dos alunos em programação

Diante dos resultados expostos no Gráfico 30 e no Gráfico 31, contata-se que, de um modo geral, tanto o grupo de docentes que possuem formação pedagógica quanto os que não possuem avaliam sua prática enquanto docente no ensino de programação como boa e os resultados de aprendizagem de seus alunos em programação como bons.

Ainda no tocante à autoavaliação, cumpre realçar que, referente à prática como docente no ensino de programação, a avaliação enquanto boa, especificamente entre o grupo de docentes sem formação pedagógica $(67,92 \%(n=36))$, é superior ao grupo que possui essa formação $(62,32 \%$ $(n=43))$. Entretanto, no que compete aos resultados de aprendizagem de seus alunos, a situação se inverte: é superior no grupo que possui formação pedagógica, correspondendo a $63,77 \%(n=44)$, e, no grupo sem formação, equivale a $62,26 \%(n=33)$.

Além disso, importa abordar que 5,66\% dos docentes sem formação avaliaram os resultados de seus alunos no aprendizado de programação como ruins, enquanto, entre os docentes que possuem formação pedagógica, somente um desses $(1,45 \%)$ avaliou dessa forma.

\section{Considerações Finais}

Frente à relevância dos computadores para a sociedade, observa-se que o fomento das habilidades relacionadas à programação de computadores tem se notabilizado. Entretanto, a literatura da área evidencia que os docentes, ao ensinar programação, obtêm menos êxito do que deveriam e precisariam ter, por diversas razões, sendo que a hipótese não deve apenas ser restrita a aspectos cognitivos dos estudantes.

Desse modo, considerando que pelo menos uma parte dos problemas relacionados ao processo de ensino/aprendizado de programação possa ter sua origem nas práticas docentes desenvolvidas, podendo elas estarem correlacionadas à formação pedagógica (ou não formação) desses docentes, este trabalho se objetivou a investigar a percepção de docentes que lecionam disciplinas concernentes à programação de computadores, quanto à formação pedagógica e ao processo de ensino/aprendizagem de programação.

Para isso, foram coletados dados de docentes das áreas de computação, informática e afins, que lecionaram alguma disciplina relacionada à programação de computadores nos últimos cinco anos, por meio de questionários em duas edições de uma formação continuada, para o ensino de programação. 
Por intermédio da análise dos dados coletados da percepção dos docentes quanto à formação pedagógica e ao processo de ensino/aprendizagem de programação, constatou-se que, em geral, os docentes com formação pedagógica participam mais de atividades direcionadas ao exercício do magistério durante a graduação, bem como possuem uma percepção positiva da preparação do ensino superior para exercer a docência, quando em comparação aos docentes que não possuem essa formação.

Além disso, averiguou-se que, mesmo a pós-graduação não se objetivando a formar docentes, ela pode contribuir, de algum modo, para a preparação de docentes ao exercício do magistério, pois tanto os docentes com formação pedagógica quanto os que não possuem essa formação consideraram que houve um preparo, pelo menos em parte, para exercer a docência nesse nível de ensino. Todavia, compete ressaltar que um elevado índice de docentes com ou sem formação considerou que a sua formação, de uma forma geral, não possibilitou um preparo para ensinar programação, sendo que essa percepção é maior entre os docentes sem formação pedagógica.

Verificou-se, também, que uma parcela significativa dos docentes com ou sem formação sentiu ou teve dificuldades em aprender a programar, estando esse resultado relativamente em consonância com a literatura da área, a qual indica as taxas de insucesso em disciplinas introdutórias de programação.

Tanto os docentes com formação pedagógica, bem como os sem formação, consideram ser importante ter uma prática docente embasada por teorias de aprendizagem e metodologias de ensino/aprendizagem. Todavia, de maneira ecumênica, os docentes com formação avaliaram seus conhecimentos como bom, enquanto os docentes sem formação avaliaram como satisfatório.

De forma universal, ao se comparar as práticas pedagógicas, conteúdos, recursos e tecnologias, instrumentos e técnicas avaliativas, além das atitudes de aprendizagem e perfil dos estudantes e turmas a que foram expostos enquanto eram estudantes e que expõem seus alunos agora como docentes, a maior parcela, tanto dos docentes com formação pedagógica quanto os sem essa formação, indicou que essa série de elementos é semelhante em muitos aspectos, porém com algumas diferenças.

A maior parcela dos dois grupos de docentes também indicou que sua prática professoral está alinhada, em parte, com a educação contemporânea e com as necessidades e perspectivas dos estudantes. Salienta-se que os grupos autoavaliaram sua prática no ensino de programação como boa e os resultados de aprendizagem de seus alunos em programação como bons.

Por fim, convém destacar que existem algumas limitações para este estudo; entre elas, destaca-se o tamanho da amostra, que compreende um total de 122 docentes. Com isso, enfatizase que esse número de participantes pode ser considerado pequeno, especialmente o universo de docentes do contexto.

\subsection{Estudos Futuros}

Para estudos futuros que prossigam na direção de examinar a possível correlação entre a formação pedagógica e o ensino/aprendizagem de programação, sugere-se o desenvolvimento de pesquisas que visem comparar as práticas de docentes com e sem formação pedagógica, bem como o desempenho de aprendizagem dos estudantes ou índices de aprovação, reprovação e evasão, particularmente quando são expostos a docentes com e sem formação pedagógica. Estudos subsidiados nesse teor têm o intuito de avaliar os impactos da formação pedagógica ou, até mesmo, a sua ausência no processo de ensino/aprendizagem de programação.

Nesse caminho, pode-se analisar, também, a preparação fornecida em cursos de licenciatura em computação, bem como formações pedagógicas de um modo geral, para o ensino de programação, tendo em vista que, conforme indicado pela amostra deste estudo, um percentual 
significativo de docentes indicou considerar que sua formação não o preparou para ensinar programação.

Cabe indicar, ainda em termos mais gerais, que a ação de investigar como as dificuldades inerentes aos docentes relacionadas ao processo de ensino/aprendizagem de programação podem implicar dificuldades concernentes aos estudantes e aos conteúdos, especialmente no que diz respeito à reprodução das práticas a que esses docentes foram expostos enquanto estudantes, pode revelar resultados significativos para o processo de ensino/aprendizagem de programação.

\section{Agradecimentos}

O presente trabalho foi realizado com apoio do CNPq, Conselho Nacional de Desenvolvimento Científico e Tecnológico - Brasil (Bolsista do CNPq 310686/2017-2).

\section{Referências}

Arimoto, M., \& Oliveira, W. (2019). Dificuldades no Processo de Aprendizagem de Programação de Computadores: um Survey com Estudantes de Cursos da Área de Computação. Anais do Workshop Sobre Educação Em Computação (WEI), 244-254. doi: 10.5753/wei.2019.6633 [GS Search]

Aureliano, V. C. O., Tedesco, P. C. de A. R., \& Giraffa, L. M. M. (2016). Desafios e oportunidades aos processos de ensino e de aprendizagem de programação para iniciantes. Anais do Workshop Sobre Educação Em Computação (WEI), 71-80. doi: 10.5753/wei.2016.9650 [GS Search]

Bennedsen, J., \& Caspersen, M. E. (2007). Failure rates in introductory programming. $A C M$ SIGCSE Bulletin, 39(2), 32-36. doi: 10.1145/1272848.1272879 [GS Search]

Bennedssen, J., \& Caspersen, M. E. (2008). Abstraction ability as an indicator of success for learning computing science? Proceeding of the Fourth International Workshop on Computing Education Research - ICER '08, May 2014, 15-26. doi: $\underline{10.1145 / 1404520.1404523}$ [GS Search]

Berssanette, J. H., \& Frencisco, A. C. (2018). Proposta de Abordagem Prática para o Ensino de Programação Baseada em Ausubel. Brazilian Symposium on Computers in Education (Simpósio Brasileiro de Informática na Educação-SBIE), 29, 398. doi: $\underline{10.5753 / \mathrm{cbie} . s b i e .2018 .398}$ [GS Search]

Bosse, Y., \& Gerosa, M. A. (2015). As Disciplinas de Introdução à Programação na USP: um Estudo Preliminar. Anais do Workshop Sobre Educação Em Computação (WEI), 1389. doi: $\underline{10.5753 / \text { cbie.wcbie.2015.1389 [GS Search] }}$

BRASIL. (1996). Lei de Diretrizes e Bases da Educação Nacional. Lei $\mathrm{n}^{\circ}$ 9.394, de 20 de dezembro de 1996. Disponível em: http://www.planalto.gov.br/ccivil_03/Leis/L9394.htm [GS Search]

Caspersen, M. E. (2007). Educating Novices in the Skills of Programming. Department of Computer Science. Daimi PhD Dissertation No. PD-07-4. Disponível em: https://www.cs.au.dk/ mec/dissertation/Dissertation.pdf [GS Search]

Costa, E. B., Fonseca, B., Santana, M. A., de Araújo, F. F., \& Rego, J. (2017). Evaluating the effectiveness of educational data mining techniques for early prediction of students' academic failure in introductory programming courses. Computers in Human Behavior, 73, 247-256. doi: 10.1016/j.chb.2017.01.047 [GS Search] 
Coutinho, E. F., Lima, E. T. de, \& Santos, C. C. (2017). Um panorama sobre o desempenho de uma disciplina inicial de programação em um curso de graduação. Revista Tecnologias $\mathrm{Na}$ Educação, 19, 1-15. Disponível em: http://tecedu.pro.br/wp-content/uploads/2017/07/Art14vol19-julho2017.pdf [GS Search]

Génova, G., \& González, M. R. (2017). Educational Encounters of the Third Kind. Science and Engineering Ethics, 23(6), 1791-1800. doi: 10.1007/s11948-016-9852-4 [GS Search]

GIRAFFA, L. M. M., \& MORA, M. da C. (2016). Evasão na disciplina de algoritmo e programação: um estudo a partir dos fatores intervenientes na perspectiva do aluno. Congresos CLABES. Disponível em: https://revistas.utp.ac.pa/index.php/clabes/article/view/888 [GS Search]

Gomes, A., \& Mendes, A. (2014). A teacher's view about introductory programming teaching and learning: Difficulties, strategies and motivations. 2014 IEEE Frontiers in Education Conference (FIE) Proceedings, 2015-Febru(February), 1-8. doi: 10.1109/FIE.2014.7044086 [GS Search]

GURER, M. D., CETIN, I., \& TOP, E. (2019). Factors Affecting Students' Attitudes toward Computer Programming. Informatics in Education, 18(2), 281-296. doi: 10.15388/infedu.2019.13 [GS Search]

Guzdial, M. (2015). Top 10 Myths about Teaching Computer Science. | Blog@CACM | Communications of the ACM. Disponível em: https://cacm.acm.org/blogs/blogcacm/189498-top-10-myths-about-teaching-computer-science/fulltext [GS Search]

Holanda, W. D. de, Freire, L. D. P., \& Coutinho, J. C. da S. (2019). Estratégias de ensinoaprendizagem de programação introdutória no ensino superior: uma Revisão Sistemática da Literatura. RENOTE, 17(1), 527-536. doi: 10.22456/1679-1916.95905 [GS Search]

INEP. (2020). Sinopse Estatística da Educação Superior 2019. Disponível em: http://inep.gov.br/sinopses-estatisticas-da-educacao-superior [GS Search]

Iqbal Malik, S., \& Coldwell-Neilson, J. (2017). Impact of a New Teaching and Learning Approach in an Introductory Programming Course. Journal of Educational Computing Research, 55(6), 789-819. doi: 10.1177/0735633116685852 [GS Search]

Koulouri, T., Lauria, S., \& Macredie, R. D. (2015). Teaching Introductory Programming: A Quantitative Evaluation of Different Approaches. ACM Transactions on Computing Education, 14(4), 1-28. doi: 10.1145/2662412 [GS Search]

Kretzer, F. M., Wangenheim, C. G. von, Hauck, J. C. R., \& Pacheco, F. S. (2020). Formação Continuada de Professores para o Ensino de Algoritmos e Programação na Educação Básica: Um Estudo de Mapeamento Sistemático. Revista Brasileira de Informática na Educação, 389-419. doi: 10.5753/RBIE.2020.28.0.389 [GS Search]

Lima, M. R. de. (2018). Concepções docentes acerca do ensino de programação de computadores no ensino superior. Teoria e Prática da Educação, 21(3), 111-122. doi: 10.4025/tpe.v21i3.45599 [GS Search]

Lopez, M. A., Duarte, E. V., Gutierrez, E. C., \& Valderrama, A. P. (2019). Teaching Based on Ludic Environments for the First Session of Computer Programming - Experience With Digital Natives. IEEE Revista Iberoamericana de Tecnologias Del Aprendizaje, 14(2), 3442. doi: 10.1109/RITA.2019.2922847 [GS Search] 
Luxton-Reilly, A., Becker, B. A., Cao, Y., McDermott, R., Mirolo, C., Mühling, A., Petersen, A., Sanders, K., Simon, \& Whalley, J. (2018). Developing Assessments to Determine Mastery of Programming Fundamentals. Proceedings of the 2017 ITiCSE Conference on Working Group Reports, 2018-Janua, 47-69. doi: 10.1145/3174781.3174784 [GS Search]

Luxton-Reilly, A., \& Petersen, A. (2017). The Compound Nature of Novice Programming Assessments. Proceedings of the Nineteenth Australasian Computing Education Conference on - $A C E$ '17, 26-35. doi: 10.1145/3013499.3013500 [GS Search]

Luxton-Reilly, A., Sheard, J., Szabo, C., Simon, Albluwi, I., Becker, B. A., Giannakos, M., Kumar, A. N., Ott, L., Paterson, J., \& Scott, M. J. (2018a). A review of introductory programming research 2003-2017. Proceedings of the 23rd Annual ACM Conference on Innovation and Technology in Computer Science Education - ITiCSE 2018, 342-343. doi: $\underline{10.1145 / 3197091.3205841}$ [GS Search]

Luxton-Reilly, A., Sheard, J., Szabo, C., Simon, Albluwi, I., Becker, B. A., Giannakos, M., Kumar, A. N., Ott, L., Paterson, J., \& Scott, M. J. (2018b). Introductory programming: a systematic literature review. Proceedings Companion of the 23rd Annual ACM Conference on Innovation and Technology in Computer Science Education - ITiCSE 2018 Companion, 55-106. doi: 10.1145/3293881.3295779 [GS Search]

Martins, V. F., Concilio, I. de A. S., \& Guimarães, M. de P. (2018). Problem based learning associated to the development of games for programming teaching. Computer Applications in Engineering Education, 26(5), 1577-1589. doi: 10.1002/cae.21968 [GS Search]

McGettrick, A., Boyle, R., Ibbett, R., Lloyd, J., Lovegrove, G., \& Mander, K. (2005). Grand Challenges in Computing: Education-A Summary. The Computer Journal, 48(1), 42-48. doi: $10.1093 / \mathrm{comjnl} / \mathrm{bxh} 064$ [GS Search]

MEC. (2016). Diretrizes Curriculares Nacionais para os cursos de Graduação em Computação (DCN16). Resolução CNE/CES No 5, de 16 de Novembro de 2016. Disponível em: http://portal.mec.gov.br/index.php?option $=$ com docman\&view $=$ download\&alias $=52101$ rces005-16-pdf\&category slug=novembro-2016-pdf\&Itemid=30192 [GS Search]

Medeiros, R. P., Ramalho, G. L., \& Falcao, T. P. (2019). A Systematic Literature Review on Teaching and Learning Introductory Programming in Higher Education. IEEE Transactions on Education, 62(2), 77-90. doi: 10.1109/TE.2018.2864133 [GS Search]

Oliveira, W., \& Cambraia, A. C. (2020). Desafios na Formação de Professores de Computação: Reflexões e Ações em Construção. Anais do XXVI Workshop de Informática Na Escola (WIE 2020), 319-328. doi: 10.5753/cbie.wie.2020.319 [GS Search]

Pattanaphanchai, J. (2019). An investigation of students' learning achievement and perception using flipped classroom in an introductory programming course: A case study of Thailand higher education. Journal of University Teaching and Learning Practice, 16(5). Disponível em: https://eric.ed.gov/?id=EJ1237873 [GS Search]

Qian, Y., \& Lehman, J. (2017). Students' Misconceptions and Other Difficulties in Introductory Programming: A Literature Review. ACM Transactions on Computing Education, 18(1), 1 24. doi: $\underline{10.1145 / 3077618}$ [GS Search]

Robins, A. (2019). Novice Programmers and Introductory Programming. In S. Fincher \& A. Robins (Eds.), The Cambridge Handbook of Computing Education Research (Cambridge Handbooks in Psychology, pp. 327-376). Cambridge: Cambridge University Press. doi: $\underline{10.1017 / 9781108654555.013}$ [GS Search] 
SBC. (2018). Educação Superior em Computação Estatísticas - 2018. Disponível em: https://www.sbc.org.br/documentos-da-sbc/send/133-estatisticas/1287-estatisticascomputacao-2018 [GS Search]

Schulte, C., \& Bennedsen, J. (2006). What do teachers teach in introductory programming? Proceedings of the 2006 International Workshop on Computing Education Research - ICER '06, 17. doi: 10.1145/1151588.1151593 [GS Search]

Silva, T. R. da, Medeiros, T., Medeiros, H., Lopes, R., \& Aranha, E. (2015). Ensino-aprendizagem de programação: uma revisão sistemática da literatura. Revista Brasileira de Informática na Educação, 23(01), 182. doi: 10.5753/rbie.2015.23.01.182 [GS Search]

Simon, Luxton-Reilly, A., Ajanovski, V. V., Fouh, E., Gonsalvez, C., Leinonen, J., Parkinson, J., Poole, M., \& Thota, N. (2019). Pass Rates in Introductory Programming and in other STEM Disciplines. Proceedings of the Working Group Reports on Innovation and Technology in Computer Science Education, 53-71. doi: 10.1145/3344429.3372502 [GS Search]

Sleeman, D. (1986). The challenges of teaching computer programming. Communications of the $A C M, 29(9), 840-841$. doi: 10.1145/6592.214913 [GS Search]

Souza, D. M., Batista, M. H. da S., \& Barbosa, E. F. (2016). Problemas e Dificuldades no Ensino de Programação: Um Mapeamento Sistemático. Revista Brasileira de Informática na Educação, 24(1), 39. doi: 10.5753/rbie.2016.24.1.39 [GS Search]

Vihavainen, A., Airaksinen, J., \& Watson, C. (2014). A systematic review of approaches for teaching introductory programming and their influence on success. Proceedings of the Tenth Annual Conference on International Computing Education Research - ICER '14, 19-26. doi: $\underline{10.1145 / 2632320.2632349}$ [GS Search]

Watson, C., \& Li, F. W. B. (2014). Failure rates in introductory programming revisited. Proceedings of the 2014 Conference on Innovation \& Technology in Computer Science Education - ITiCSE '14, 39-44. doi: 10.1145/2591708.2591749 [GS Search]

Yousoof, M., \& Sapiyan, M. (2016). Customized instructional pedagogy in learning programming - Proposed model. Journal of Theoretical and Applied Information Technology, 85(3), 309320. Disponível em: http://www.jatit.org/volumes/Vol85No3/8Vo185No3.pdf [GS Search]

Zorzo, A. F., Nunes, D., Ecivaldo, S., \& Martins, S. (2017). Referenciais de Formação para os Cursos de Graduação em Computação. Sociedade Brasileira de Computação (SBC). Disponível em: https://www.sbc.org.br/documentos-da-sbc/send/127-educacao/1155$\underline{\text { referenciais-de-formacao-para-cursos-de-graduacao-em-computacao-outubro-2017 [GS }}$ Search] 